FACULTY OF ECONOMICS AND APPLIED ECONOMIC SCIENCES

CENTER FOR ECONOMIC STUDIES

ENERGY, TRANSPORT \& ENVIRONMENT

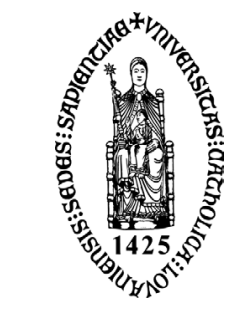

KATHOLIEKE UNIVERSITEIT

LEUVEN

WORKING PAPER SERIES

$n^{\circ}$ 2003-17

\title{
Coalition Formation in a Global Warming Game: How the Design of Protocols Affects the Success of Environmental Treaty-Making
}

\section{Johan Eyckmans (KU.Leuven - CES; EHSAL Europese Hogeschool Brussel) \\ Michael Finus (Department of Economics, University of Hagen)}

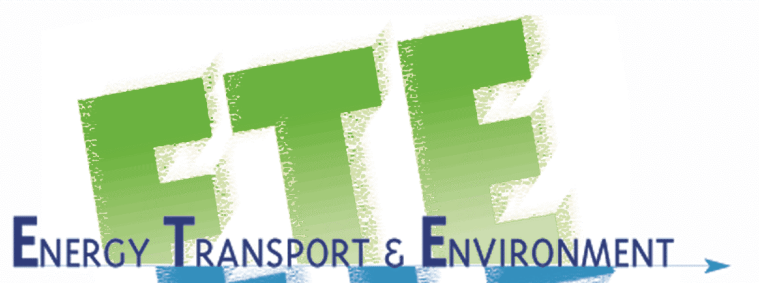

secretariat:

Isabelle Benoit

KULeuven-CES

Naamsestraat 69, B-3000 Leuven (Belgium)

$$
\begin{array}{lll}
\text { tel: } & \quad+32(0) & 1632.66 .33 \\
\text { fax: } & +32(0) & 1632.69 .10
\end{array}
$$

e-mail: Isabelle.Benoit@econ.kuleuven.ac.be http://www.kuleuven.be/ete 


\title{
Coalition Formation in a Global Warming Game: How the Design of Protocols Affects the Success of Environmental Treaty-Making
}

\author{
First draft: March, 2003 \\ Johan Eyckmans \\ K.U.Leuven, Centrum voor Economische Studiën, \\ Naamsestraat 69, B-3000 Leuven, Belgium \\ Johan.Eyckmans@econ.kuleuven.ac.be \\ Michael Finus \\ Department of Economics, University of Hagen, \\ Profilstr. 8, 58084 Hagen, Germany \\ Michael.Finus@fernuni-hagen.de
}

\begin{abstract}
We combine the newest concepts of non-cooperative coalition theory with a computable general equilibrium model close to the seminal RICE-model of Nordhaus and Yang (1996) to determine stable coalition structures in a global warming game. We consider three coalition games that allow for the formation of multiple coalitions. The coalition games represent different designs of climate treaty protocols. Counterintuitively, it turns out that treaties based on a unanimous decision rule and exclusive membership lead to superior outcomes than treaties with open membership. We also demonstrate that if coalition formation is not restricted to a single coalition, as this has been done previously in the literature, coalition structures with multiple coalitions will emerge in equilibrium. Most of the regional agreements are superior to single agreements. Moreover, our findings confirm those derived from simpler theoretical models that a cleverly designed transfer scheme can foster cooperation and that from the number of participants the success of a treaty cannot be inferred. They also support a conjecture of theory that in the case of greenhouse gases stable coalition structures (partial cooperation) can close the gap between the global optimum (full cooperation) and the Nash equilibrium (no cooperation) by a substantial amount.
\end{abstract}

JEL-Classsification: C68, C72, H41, Q25

Keywords: design of climate treaty protocol, coalition formation, non-cooperative game theory 


\section{Introduction}

In the literature on the economics of global warming two strands of the literature can be distinguished. The empirical strand comprises cost-benefit analyses (CBA) and costeffectiveness analyses (CEA). Important research topics include methodological and conceptual issues on estimating abatement costs (e.g., Weyant 1999 or IPCC 2001) and damage costs (e.g., Tol 2002a, b), the determination of optimal global abatement levels and efficient allocation of abatement burdens (e.g., d'Arge et al. 1982 and Nordhaus 1991) as well as distributional implications of various abatement policies (e.g., Chichilnisky and Heal 1994 and Eyckmans et al. 1993). In recent years computational general equilibrium models (CGEmodels) have been developed that take many dynamic aspects of climate change as well as the relation and feedback between the climate and the economic system into account (see, e.g., Nordhaus and Yang 1996 for the seminal RICE model). The importance of this literature lies in identifying globally optimal and cost-efficient abatement policies, providing information on expected impacts of various climate policies on the economy and the ecological system, as well as identifying the gainers and losers in a cooperative "global warming game". However, in terms of stability of climate treaties this literature has little to say. Though it is certainly true that a necessary condition for a country to accede to a treaty is that it benefits from participation, it is by no means a sufficient condition. Even if countries would gain from signing a treaty they may nevertheless decide to pursue a non-cooperative policy. Due to the public good nature of the global warming problem, free-riding is attractive since the abatement contribution of a single country has only a marginal impact on reducing damage costs from greenhouse gas concentration but has a substantial impact on its abatement costs.

In contrast, the theoretical strand of the literature comprises game theoretical analyses on the formation and stability of international environmental agreements (IEAs). ${ }^{1}$ The importance of this literature lies in pointing out the difficulties in designing self-enforcing agreements, taking into account that cooperation requires a high amount of consensus because of voluntary participation of countries and a successful agreement must neutralize various free-rider incentives. Repeated game models have stressed the importance of credible threats of punishment to enforce compliance in IEAs (e.g., Barrett 1994 and 2000, Finus/Rundshagen 1998, Finus/Tjotta 2002 and Stähler 1996). One main finding is that due to the lack of credible punishments compliance can only be ensured for very moderate abatement targets and there might be a trade-off between efficiency, effectiveness and stability. A conceptual drawback of these models is that the coalition formation process receives little attention and

An extensive overview is provided in Finus (2001 and 2003). 
that stock pollutants cannot be analyzed. In contrast, coalition models analyze participation in IEAs applying cooperative and non-cooperative game theoretical stability concepts. Cooperative game theory, which is mainly normatively oriented, focused on transfer schemes that ensure stability of the (efficient) grand coalition by applying the stability concept of the core (e.g., Chander and Tulkens 1995 and 1997 and Germain et al. 2000). A central result is that there exists a transfer scheme, which allocates the gains from cooperation in proportion to the marginal benefits of reduced environmental damages, ensuring stability of an efficient environmental policy (see section 3). A conceptual drawback of the cooperative approach is that it only tests stability of the grand coalition, analysis stability in terms of the aggregate payoff to coalitions and rests on very strong assumptions about the implicit punishment after free-riding of a group of countries. However, the amount of empirical studies is relatively large and most rely on a sound empirical module (e.g., Eyckmans and Tulkens 1999, Germain et al. 1998 and Kaitala et al. 1995).

Non-cooperative game theory, which is mainly positively oriented, tried to rationalize the problems of forming large and effective coalitions by applying the concept of internal and external stability (e.g., Barrett 1994, Carraro/Siniscalco 1993, Hoel 1992 and Hoel/Schneider 1997). A key result is that whenever cooperation (social optimum) would generate large global welfare gains compared to a non-cooperative situation (Nash equilibrium), stable coalitions achieve only little and vice versa. Moreover, it is pointed out that from participation one cannot conclude success of cooperation: small coalitions may achieve more than large coalitions in terms of global welfare and emission reduction. A conceptual drawback of internal\&external stability is that it exogenously restricts coalition formation to one (nontrivial) coalition. Moreover, most models rely on very specific assumptions to derive their results. ${ }^{2}$ Finally, there are only few empirical studies but they compromise on the empirical part for tractability (e.g., Botteon/Carraro 1997 and 1998 and Tol 2001).

Recently, there has been a development of new approaches and concepts in non-cooperative game theory that has been termed "new coalition theory" (Finus 2002). ${ }^{3}$ Compared to the cooperative approach it has two advantages. First, its seems natural to assume that rational agents will base their decision of participation in an IEA on individual payoffs and not on the

2 Typical assumptions include for instance a static payoff structure and identical welfare functions (symmetric players). An exception is Rubio/Ulph (2001) who consider a dynamic game but symmetric players and Barrett (1997) who considers heterogeneous players but uses simulations to derive results.

3 For an excellent overview see Bloch (1997) and Yi (1997). 
aggregate payoff to their coalition even if in the case of transfers. Second, it explicitly takes into account spillovers between coalitions through a valuation function (see section 2). Since spillovers are an important source of free-riding, inefficient agreements can be better rationalize. Compared to the non-cooperative concept of internal\& external stability these new developments have the advantage that they do not restrict coalition formation to a single non-trivial coalition ex-ante but allow for the co-existence of multiple coalitions. Finally, compared to the "classical" cooperative and non-cooperative approaches, new coalition theory draws a conceptual line between the rules of coalition formation and stability. Since the rules of coalition formation can be interpreted as the institutional setting in which treaty formation take place (Carraro/Marchiori/Oreffice 2001 and Ecchia/Mariotti 1998), policy conclusions about the optimal design of protocols are possible. Moreover, the reaction of countries after a deviation do not follow from ad hoc assumptions but follow from the rules of coalition formation and can therefore be related to the rational behavior of agents.

The philosophy of this paper is to combine a fully fledged empirical model with aspects of new coalition theory as this has been done recently by Eyckmans (2001) in order to analyze stable climate change coalitions. The purpose is to relate the design of protocols to the success coalition formation. We proceed as follows. In section 2 we lay out the game theoretical setting and in section 3 we describe the empirical module of our model. Equilibrium coalition structures are reported and evaluated in section 4. Section 5 summarizes our main findings and concludes with some final remarks.

\section{The Game Theoretical Model}

\subsection{Introduction}

Coalition formation is modeled as a two-stage game. In the first stage players (i.e., countries or regions) decide on their membership in a coalition, in the second stage coalition members choose their economic strategies. The decision in the first stage depends on the rules of coalition formation that follow from the definition of a coalition game. The definition comprises three elements: 1) the set of players $I=\{1, \ldots, N\}$ with a particular player denoted by index $\mathrm{i}$ or $\mathrm{j}, 2$ ) the set of coalition (or, alternatively, membership or announcement) strategies $\Sigma=\Sigma_{1} \times \Sigma_{2} \times \ldots \times \Sigma_{\mathrm{N}}$ with a particular strategy of player $\mathrm{i} \in \mathrm{I}$ denoted by $\sigma_{\mathrm{i}} \in \Sigma_{\mathrm{i}}$, and 3) a coalition function $\psi$ that maps membership strategies $\sigma=\left(\sigma_{1}, \ldots, \sigma_{\mathrm{N}}\right)$ into coalition structures, $\psi: \Sigma \rightarrow \mathrm{C}: \sigma \mapsto \psi(\sigma)$. A coalition structure $\mathrm{c}=\left(\mathrm{c}^{1}, \ldots, \mathrm{c}^{\mathrm{M}}\right)$ is a partition of players where a particular coalition is denoted by $\mathrm{c}^{\mathrm{k}}, \mathrm{k} \in\{1, \ldots, \mathrm{M}), \mathrm{c}^{\mathrm{k}} \cap \mathrm{c}^{1}=\varnothing \forall \mathrm{k} \neq 1, \bigcup \mathrm{c}^{\mathrm{k}}=\mathrm{I}$ and $\mathrm{c} \in \mathrm{C}$ where $\mathrm{C}$ is the set of all possible coalition structures. 
The decision in the second stage depends on the rules how players choose their economic strategies that follow from the definition of the valuation function. The valuation function $\mathrm{v}(\mathrm{c})$ maps coalition structures into a vector of individual payoffs (i.e., welfare) via an instruction how players choose their economic strategies $s_{i} \in S_{i}, S_{i} \in S=S_{1} \times S_{2} \times \ldots \times S_{N}$, for a given coalition structure $\mathrm{c}$. Hence, the valuation function is a composition of two functions $\mathrm{v}=\mathrm{w} \circ \varepsilon$ where $\varepsilon: \mathrm{C} \rightarrow \mathrm{S}: \mathrm{c} \mapsto \varepsilon(\mathrm{c})$ is a function mapping coalition structures into economic strategies and $\mathrm{w}: \mathrm{S} \rightarrow \mathbb{R}^{\mathrm{N}}: \mathrm{s} \mapsto \mathrm{w}(\mathrm{s})$ is a function mapping economic strategies into welfare levels.

For the first stage we consider three different coalition games, representing three different institutional rules how coalitions form. For the second stage we consider only one rule that assigns a unique vector of individual payoffs for each possible coalition structure. This implies that players choosing a membership strategy in the first stage know for each coalition game the implications in the second stage. Hence, games can be solved by backwards induction. Consequently, we start in the following by describing first stage 2 and subsequently we move on to explain stage 1 of the coalition formation game.

\subsection{Second Stage of the Coalition Formation Game}

Let the welfare function of player $i$ in the global warming game be given by $\mathrm{w}_{\mathrm{i}}(\mathrm{s})$ where $\mathrm{s}$ is a vector of economic strategies. That is, welfare of player $i$ depends on his own strategy $s_{i}$ and those of other players, $s_{-i}$. The exact relationship between economic strategies (e.g. emission abatement and captial investment) and welfare as well as the elements in players' welfare function will be outlined in section 3. For the valuation function - mapping coalition structures into payoffs - we make the following standard assumptions (Bloch 1997):

\section{Definition 1: Valuation Function}

Fix a coalition structure $c=\left(c^{l}, \ldots, c^{M}\right)$, let $v(c)=\left\{v_{i}(c)\right\}_{i \in I}=\left\{w_{i}(\varepsilon(c))\right\}_{i \in I}=\left\{w_{i}\left(s^{*}\right)\right\}_{i \in I}$ and assume for instruction $\varepsilon$ that all players belonging to a coalition $c^{k} \in c$ jointly maximize the aggregate payoff to their coalition. Let $s^{k}$ denote the economic strategy vector of coalition $c^{k}$ and $s^{-k}$ the economic strategy vector of all other coalitions $c^{l} \in c, l \neq k$, and assume that equilibrium economic strategy vector $s^{*}=\varepsilon(c)$ for coalition structure $c$ satisfies:

$\forall c^{k} \in C, \forall s^{k} \in S^{k}: \sum_{i \in c^{k}} w_{i}\left(s^{*}\right) \geq \sum_{i \in c^{k}} w_{i}\left(s^{k}, s^{-k^{*}}\right)$ where $s^{*}$ is a unique interior equilibrium.

Definition 1 implies that the valuation of player $i, v_{i}(c)$, is identified by the entire coalition structure $\mathrm{c}$ and not only by the coalition to which he belongs. Players behave cooperatively 
within their coalition but non-cooperatively against players belonging to other coalitions when choosing their economic strategies. Put differently, members of a coalition act as one single player maximizing the aggregate welfare to their coalition and coalitions play a Nash equilibrium strategy in terms of economic strategies. Hence, economic strategies within a coalition are efficiently chosen. Consequently, the singleton coalition structure (grand coalition) implies an equilibrium economic strategy vector corresponding to the "classical" Nash equilibrium (social optimum). ${ }^{4}$ Thus, the highest global welfare will be obtained in the grand coalition, the lowest in the single coalition structure and any welfare level in between in any other coalition structure. For the properties of the welfare function that we define in section 3 it turns out that $s^{*}$ is unique and lies well within the boundaries of the economic strategy space.

Definition 1 implicitly assumes no transfers. This is one option that we consider in our simulations below, which we call the "no transfer case". Alternatively, we consider a second option to which we refer to as the "transfer case". Of course, there are many possibilities how the gains of cooperation could be distributed among coalition members as for instance the Shapley value (Barrett 1997, Botteon and Carraro 1997) or the Chander/Tulkens' transfer scheme (Chander and Tulkens 1997). We restrict ourselves to a modified version of the last transfer scheme of which the details will be laid out in section 3. At this stage it suffices to point out that this transfer scheme assumes a particular rule how the surplus from cooperation within a coalition is distributed. Hence, $\hat{v}_{i}(c)=v_{i}(c)+t_{i}$ where $t_{i}>0$ implies that a player receives a transfer and $t_{i}<0$ that a player pays a transfer.

\subsection{First Stage of the Coalition Formation Games}

In this subsection we define and discuss three coalition games that imply different rules how coalitions can form. All games assume that countries simultaneously announce their coalition strategy and allow for the co-existence of several coalitions. That is, coalition formation is not ex-ante restricted to a single coalition as this is assumed for the concepts of internal\&external stability and the core that have been widely applied in the literature on IEAs. However, games differ in the strategy set and most importantly in the coalition function that maps coalition strategies into coalition structures.

4 The grand coalition is that coalition structure where all players are in one coalition and will be denoted by $c^{\mathrm{s}}$. The singleton coalition structure implies that every player forms a (trivial) coalition by himself and is denoted by $\mathrm{c}^{\mathrm{N}}$. 
The first game is called open membership game (OMG) and is due to Yi/Shin (1995). In this game players can freely form coalitions as long as no outsider is excluded from joining a coalition. Players choose their membership by announcing an address, i.e., a number between 1 and N. Players that have announced the same address form a coalition. For instance, suppose $\mathrm{N}=6$ and $\sigma_{1}=\sigma_{2}=\sigma_{3}=1, \sigma_{4}=2, \sigma_{5}=\sigma_{6}=3$, then $\mathrm{c}=\{\{1,2,3\},\{4\},\{5,6\}\}$ forms. If player 3 were to announce $\sigma_{3}=2$ instead, then $c^{\prime}=\{\{1,2\},\{3,4\},\{5,6\}\}$ would form. More formally, we have: ${ }^{5}$

\section{Definition 2: Open Membership Game (OMG)}

a) The set of coalition strategies of player $i \in I$ is given by $\Sigma_{i}=\{1, \ldots, N\}$ where a particular strategy $\sigma_{i}$ is an announcement of an address.

b) Coalition function $\psi^{O M G}$ maps strategy vector $\sigma$ into coalition structure $c$ as follows: $c^{i}=\{i\} \cup\left\{j / \sigma_{i}=\sigma_{j}\right\}$.

Thus in the OMG a player can join any coalition he wants. This strong assumption, however, seems not entirely in line with the notion of voluntary participation in all IEAs. For instance, the US and developing countries cannot be forced into the Kyoto Protocol. Hence, it seems natural to consider an extension of the OMG where players have only unrestricted open access to non-trivial coalitions but require the consent of a singleton player if they intend to join him. This extension is called a restricted open membership game (ROMG) and has been proposed by Bloch (1997) and formalized by Rundshagen (2002). Conceptually, only a slight modification of Definition 2 is required, adding to the strategy set an address 0 and specifying the coalition function such that players announcing 0 remain singletons.

\section{Definition 3: Restricted Open Membership Game (ROMG)}

a) The set of coalition strategies set of player $i$ is given by $\Sigma_{i}=\{0,1, \ldots, N\}$ where a particular strategy $\sigma_{i}$ is an announcement of an address. and $c_{i}$ the coalition to which $i$ finally belongs, $i=1, \ldots, N$, then $c_{i}=\{i\} \cup\left\{j / \sigma_{i}^{m}=\sigma_{j}^{m} \neq 0\right\}$.

b) Coalition function $\psi^{R O M G}$ maps strategy vector $\sigma$ into coalition structure c as follows:

$c^{i}=\{i\} \cup\left\{j / \sigma_{i}=\sigma_{j} \neq 0\right\}$.

For instance, recall our previous example that assumed $\sigma_{1}=\sigma_{2}=\sigma_{3}=1, \sigma_{4}=2$, $\sigma_{5}=\sigma_{6}=3$, so that $\mathrm{c}=\{\{1,2,3\},\{4\},\{5,6\}\}$ forms and where we argued that if player 3

5 The open membership rule of this game is similar as implied by internal\&external stability, except that in the OMG multiple coalitions may form. For details see Finus/Rundshagen (2001a). 
changes his address to $\sigma_{3}=2$, then $c^{\prime}=\{\{1,2\},\{3,4\},\{5,6\}\}$ will come about. In the ROMG player 4 can announce $\sigma_{4}=0$ instead of $\sigma_{4}=2$ so that no other player can force him into a coalition. However, also in the ROMG, any player not in coalition $\{1,2,3\}$ can join this coalition and also any player not in coalition $\{5,6\}$ can accede to this coalition. This is different in the next game.

In the exclusive membership game (EMG), which is due to Hart/Kurz (1983), players announce a list of players with whom they would like to form a coalition. ${ }^{6}$ Those players with the same list form a coalition. For instance, suppose $N=6$ and $\sigma_{1}=\sigma_{2}=\{1,2,3\}, \sigma_{3}=\{3\}$, $\sigma_{4}=\{4,5,6\}$ and $\sigma_{5}=\sigma_{6}=\{5,6\}$, then $c=\{\{1,2\},\{3\},\{4\},\{5,6\}\}$ forms. Players 1 and 2 have the same list and therefore form a coalition. The same is true for players 5 and 6 . Players 3 and 4 remain singletons. Player 3 is a singleton by its own will and cannot be forced into a coalition with players 1 and 2 and player 4 is a singleton against his will since he is not on the list of players 5 and 6 . In both cases, players are singletons since membership is exclusive. In other words, a coalition only forms by unanimous agreement. More formally, we have:

\section{Definition 4: Exclusive Membership Game (EMG)}

a) The set of coalition strategies of country $i \in I$ is given by $\Sigma_{i}=\left\{c^{i} \subset I / i \in c^{i}\right\}$ where a particular strategy $\sigma_{i}$ is a list of countries with which country $i$ would like to form a coalition.

b) Coalition function $\psi^{E M \Delta G}$ maps strategy vector $\sigma$ into coalition structure $c$ as follows: $c^{i}=\{i\} \cup\left\{j / \sigma_{i}=\sigma_{j}\right\}$.

In the same spirit as we defined an equilibrium in economic strategies in the second stage of the coalition formation process, it remains to define an equilibrium in coalition strategies in the first stage of the game. This task is straightforward since, again, we use the definition of a Nash equilibrium but now in the context of coalition strategies.

\section{Definition 5: Stable Coalition Structures}

Consider a particular coalition function $\psi$ and valuation function $v$. Coalition structure $c^{*}$ is said to be stable if there exists a coalition strategy $\sigma^{*} \in \Sigma$ generating $c^{*}$ such that $\forall i \in I$ and $\forall \sigma_{i} \in \Sigma_{i}: v_{i}\left(\psi\left(\sigma^{*}\right)\right) \geq v_{i}\left(\psi\left(\sigma_{i}, \sigma_{-i}^{*}\right)\right)$

Hence, a coalition structure is called stable if it can be supported by an announcement strategy vector that constitutes a Nash equilibrium for the first stage of the coalition formation game.

6 Our definition corresponds to what is called $\Delta$-game by Hart/Kurz (1983). 
Denoting stable coalition structures in the coalition games by $\mathrm{C}^{\mathrm{S}}(\mathrm{OMG}), \mathrm{C}^{\mathrm{S}}(\mathrm{ROMG})$ and $\mathrm{C}^{\mathrm{S}}(\mathrm{EM} \Delta \mathrm{G})$, respectively, then from theory it is known that $\mathrm{C}^{\mathrm{S}}(\mathrm{OMG}) \subset \mathrm{C}^{\mathrm{S}}(\mathrm{ROMG})$ $\subset C^{S}(E M G)$ holds (Finus and Rundhagen 2003). The intuition of this relation is simple: in all games the amount of possible deviations is the same, except that in the ROMG players can not join singletons without their consent, which is possible in the OMG. By the same token, in the EMG players cannot join a coalition without their consent, which is possible in the ROMG (and in the OMG). Thus, if a coalition structure is not stable in the EMG, then it cannot be stable in the ROMG and if a coalition structure is not stable in the ROMG, then it cannot be stable in the OMG. However, what is not known from theory (except for very restrictive assumptions on payoff functions) ${ }^{7}$ is whether those coalition structures which are stable in the ROMG (EMG) but not in the OMG (ROMG) will be superior in welfare or ecological terms. Hence, it will be of particular interest in section 4 to evaluate and compare stable coalition structures in the various games from this perspective. Since it will turn out in section 4 that in the EMG the set of stable coalitions is relatively large in the "transfer case", we introduce an equilibrium refinement. This refinement is simple and requires from a stable coalition structure that it is Pareto-undominated by another stable coalition structure.

\section{Definition 6: Pareto-undominated Stable Coalition Structures}

Let $c^{S} \in C^{S}$ be stable coalition structure in some coalition game, then $c^{S}$ is called a Paretoundominated stable coalition structure if there is no other coalition structure $c^{S^{\prime}} \in C^{S}$ where at least one player is better off and no player is worse off, i.e., there is no $c^{s^{\prime}} \in C^{S}$ such that $\forall$ $i \in I: v_{i}\left(c^{S^{\prime}}\right) \geq v_{i}\left(c^{S}\right)$ and $\exists j \in I: v_{j}\left(c^{S^{\prime}}\right)>v_{j}\left(c^{S}\right)$.

\section{The Empirical Model}

\subsection{The CLIMNEG World Simulation Model}

The CLIMNEG World Simulation Model (in the sequel referred to as CWSM) is an integrated assessment, economy-climate model that resembles closely the seminal RICE model by Nordhaus and Yang (1996). The main difference compared to RICE is that utility is linear in consumption which is necessary to perform game theoretic analyses in a transferable utility (TU) framework. We give here only a short overview of CWSM, a more detailed description and motivation can be found in Eyckmans and Tulkens (1999). The key functions and parameters are provided in the Appendix. An important feature of integrated assessment

See for instance Finus/Rundshagen (2001a). Restrictive assumptions are for instance a static payoff structure, identical payoff functions of countries (symmetric players) and orthogonal reaction functions that do not hold in our empirical global warming game. See section 3 . 
models is the endogenous feedback of climate change damages on production and consumption possibilities. The economic part of CWSM consists of a longterm dynamic, perfect foresight Ramsey type of optimal growth model with endogenous investment and carbon emission reduction decisions. The carbon cycle and temperature change module are the same as in RICE.

In the CWSM, the World is divided into six regions: USA, JPN (Japan), EU (European Union), CHN (China), FSU (Former Soviet Union) and ROW (Rest of the World). In each of these regions and in every time period the following regional budget equation describes how gross production, $Y_{i, t}$, can be allocated to consumption, $Z_{i, t}$, investment, $I_{i, t}$, emission abatement costs, $Y_{i, t} C_{i}\left(\mu_{i, t}\right)$, and climate change damages, $Y_{i, t} D\left(\Delta T_{t}\right)$ :

$$
Y_{i, t}=Z_{i, t}+I_{i, t}+Y_{i, t} C_{i}\left(\mu_{i, t}\right)+Y_{i, t} D_{i}\left(\Delta T_{t}\right)
$$

Gross production can be interpreted as "potential GDP", that is, what could be produced in the absence of the climate change problem. Abatement costs are an increasing and convex function of emission abatement effort $\mu_{\mathrm{i}, \mathrm{t}} \in[0,1]$. Abatement effort measures the relative emission reduction compared to the Business-as-usual scenario (BAU) without any abatment policy. Climate change damages are an increasing and convex function of temperature change $\Delta \mathrm{T}_{\mathrm{t}}$. Abatement costs, $\mathrm{C}_{\mathrm{i}}\left(\mu_{\mathrm{i}, \mathrm{t}}\right)$, and climate change damages, $\mathrm{D}_{\mathrm{i}}\left(\Delta \mathrm{T}_{\mathrm{i}}\right)$, are treated as proportions of "potential production". Hence, total costs and damages are the product of costs and damages with "potential" production $\mathrm{Y}_{\mathrm{i}, \mathrm{t}}$, respectively. Rewriting (1) allows interpreting the lefthand side of the budget equation as "green GDP", that is, production net of climate change damages and abatement costs:

$$
\mathrm{Y}_{\mathrm{i}, \mathrm{t}}\left[1-\mathrm{C}_{\mathrm{i}}\left(\mu_{\mathrm{i}, \mathrm{t}}\right)-\mathrm{D}_{\mathrm{i}}\left(\Delta \mathrm{T}_{\mathrm{t}}\right)\right]=\mathrm{Z}_{\mathrm{i}, \mathrm{t}}+\mathrm{I}_{\mathrm{i}, \mathrm{t}}
$$

Every region is characterized by a production function $\mathrm{F}$ that maps combinations of capital stock $\mathrm{K}_{\mathrm{i}, \mathrm{t}}$ and labour input $\mathrm{L}_{\mathrm{i}, \mathrm{t}}$ into output. The production technology is assumed to satisfy constant returns to scale of the Cobb-Douglas type:

$$
\mathrm{Y}_{\mathrm{i}, \mathrm{t}}=\mathrm{a}_{\mathrm{i}, \mathrm{t}} \mathrm{F}\left(\mathrm{K}_{\mathrm{i}, \mathrm{t}}, \mathrm{L}_{\mathrm{i}, \mathrm{t}}\right) \equiv \mathrm{F}_{\mathrm{i}, \mathrm{t}}\left(\mathrm{K}_{\mathrm{i}, \mathrm{t}}\right)
$$

where $a_{i, t}$ is a technology shift parameter that is assumed to increases exogenously over time. Labour supply is assumed to be inelastic. Incorporating the technology parameter and labour input into the production function, gives a "new" production function $\mathrm{F}_{\mathrm{i}, \mathrm{t}}\left(\mathrm{K}_{\mathrm{i}, \mathrm{t}}\right)$.

Capital accumulation is described in the standard way:

$$
\mathrm{K}_{\mathrm{i}, \mathrm{t}+1}=\left[1-\delta_{\mathrm{K}}\right] \mathrm{K}_{\mathrm{i}, \mathrm{t}}+\mathrm{I}_{\mathrm{i}, \mathrm{t}}
$$


where $\delta_{\mathrm{K}}$ denotes the capital depreciation rate. Production gives rise to emissions of greenhouse gases. In the CWSM, emissions are propotional to "potential" output:

$$
E_{i, t}=\alpha_{i, t}\left[1-\mu_{i, t}\right] Y_{i, t}
$$

where the exogenous parameter $\alpha_{i, t}$ denotes the emission-ouput ratio and is assumed to decline over time due to exogenous energy efficiency improvements. Emissions accumulate in the atmosphere according to a standard linear stock externality accumulation process:

$$
\mathrm{M}_{\mathrm{t}+1}=\left[1-\delta_{\mathrm{M}}\right] \mathrm{M}_{\mathrm{t}}+\beta \sum_{\mathrm{i} \in \mathrm{N}} \mathrm{E}_{\mathrm{i}, \mathrm{t}}
$$

where $\mathrm{M}$ denotes carbon concentration, $\delta_{\mathrm{M}}$ the natural decay rate and $\beta$ the airborn fraction of emissions, that is, the fraction of emissions added to atmospheric concentrations. Carbon concentration is translated into temperature change according to an increasing function $\mathrm{G}$ :

$$
\Delta \mathrm{T}_{\mathrm{t}}=\mathrm{G}\left(\mathrm{M}_{\mathrm{t}}\right)
$$

Welfare of each country is measured by its aggregate lifetime discounted consumption:

$$
\mathrm{w}_{\mathrm{i}}(\mathrm{s})=\sum_{\mathrm{t}=0}^{\Omega} \frac{\mathrm{Z}_{\mathrm{i}, \mathrm{t}}}{\left[1+\rho_{\mathrm{i}}\right]^{\mathrm{t}}}
$$

where $\rho_{\mathrm{i}}$ stands for the discount rate of region i and $\Omega$ denotes the time horizon. The strategy vector s consists of a time path (35 decades, starting in 1990) for emission abatement and investment for all six regions, $s=\left\{I_{i, t}, \mu_{i, t}\right\}_{i \in N ; t=0, \ldots, \Omega}$, and hence is of length $2 \times 35 \times 6=420$.

\subsection{Computing Valuations}

Recall from Definition 1 that the valuation function maps coalition structures $\mathrm{c}=\left(\mathrm{c}^{1}, \ldots, \mathrm{c}^{\mathrm{M}}\right) \in \mathrm{C}$ into payoffs, $\mathrm{v}_{\mathrm{i}}(\mathrm{c})=\mathrm{w}_{\mathrm{i}}(\varepsilon(\mathrm{c}))=\mathrm{w}_{\mathrm{i}}\left(\mathrm{s}^{*}\right)$, via an instruction how players choose their economic strategies s. For a fixed coalition structure c, Definition 1 assumes that coalition members jointly maximize the aggregate welfare to their coalition and that equilibrium economic strategies constitute a Nash equilibrium. Thus, coalition $\mathrm{c}^{\mathrm{k}}$ chooses an investment and emission abatement strategy vector $\mathrm{s}^{\mathrm{k}}=\left\{\mathrm{I}_{\mathrm{i}, \mathrm{t}}, \mu_{\mathrm{i}, \mathrm{t}}\right\}_{\mathrm{i} \in \mathrm{c}^{\mathrm{k}} ; \mathrm{t}=0, \ldots, \Omega}$ in order to maximize the aggregate discounted welfare over all periods for given strategies $\mathrm{s}^{-\mathrm{k}}$ of other countries (that is, given emission paths $\overline{\mathrm{E}}_{\mathrm{i}, \mathrm{t}}$ ). Formally: 


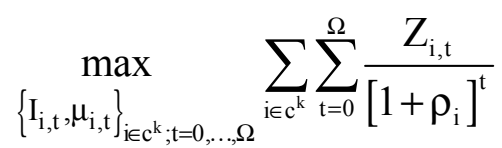

$$
\begin{aligned}
& \text { s.t. } \sum_{\mathrm{i} \in \mathrm{c}^{\mathrm{k}}} \mathrm{F}_{\mathrm{i}, \mathrm{t}}\left(\mathrm{K}_{\mathrm{i}, \mathrm{t}}\right)\left[1-\mathrm{C}_{\mathrm{i}}\left(\mu_{\mathrm{i}, \mathrm{t}}\right)-\mathrm{D}_{\mathrm{i}}\left(\mathrm{G}\left(\mathrm{M}_{\mathrm{t}}\right)\right)\right]=\sum_{\mathrm{i} \in \mathrm{c}^{\mathrm{k}}}\left[\mathrm{Z}_{\mathrm{i}, \mathrm{t}}+\mathrm{I}_{\mathrm{i}, \mathrm{t}}\right] \\
& \mathrm{M}_{\mathrm{t}+1}=\left[1-\delta_{\mathrm{M}}\right] \mathrm{M}_{\mathrm{t}}+\beta \sum_{\mathrm{i} \in \mathrm{c}^{\mathrm{k}}} \alpha_{\mathrm{i}, \mathrm{t}}\left[1-\mu_{\mathrm{i}, \mathrm{t}}\right] \mathrm{F}_{\mathrm{i}, \mathrm{t}}\left(\mathrm{K}_{\mathrm{i}, \mathrm{t}}\right)+\beta \sum_{\mathrm{j} \in \mathrm{c}^{\mathrm{k}}} \overline{\mathrm{E}}_{\mathrm{j}, \mathrm{t}}
\end{aligned}
$$

This gives rise to two first oder conditions of country $i$ being a member of coalition $c^{k}$ in coalition structure $\mathrm{c}$ at time $\mathrm{t}$ :

$$
\frac{1}{\left[1+\rho_{\mathrm{i}}\right]^{\mathrm{t}}} \frac{\mathrm{C}_{\mathrm{i}}{ }^{\prime}\left(\mu_{\mathrm{i}, \mathrm{t}}\right)}{\alpha_{\mathrm{i}, \mathrm{t}}}=\beta \sum_{\mathrm{i} \in \mathrm{c}^{\mathrm{k}}} \sum_{\tau=t+1}^{\Omega} \frac{\mathrm{F}_{\mathrm{i}, \tau}\left(\mathrm{K}_{\mathrm{i}, \tau}\right) \mathrm{D}_{\mathrm{i}, \tau}{ }^{\prime}\left(\Delta \mathrm{T}_{\tau}\right)}{\left[1+\rho_{\mathrm{i}}\right]^{\tau}} \mathrm{G}_{\tau}^{\prime}\left(\mathrm{M}_{\tau}\right)\left[1-\delta_{\mathrm{M}}\right]^{\tau-t-1}
$$

That is, country $\mathrm{i}$ at time $\mathrm{t}$ chooses its abatement effort such that discounted marginal abatement costs equal the sum of all coalition members' discounted marginal climate change damages, taking into account the sensitivity of the climate system and the natural decay of atmospheric carbon concentrations. This is a dynamic version of the Samuelson rule for the optimal provision of public goods, though here restricted to members of coalition $\mathrm{c}^{\mathrm{k}}$. Coalition members internalize only their benefits of emission control but not of outsiders. The second first-order condition from which the optimal capital accumulation is derived is given by:

$$
\rho_{\mathrm{i}}=\mathrm{F}_{\mathrm{i}, \mathrm{t}}{ }^{\prime}\left(\mathrm{K}_{\mathrm{i}, \mathrm{t}}\right)\left\{1-\mathrm{C}_{\mathrm{i}}\left(\mu_{\mathrm{i}, \mathrm{t}}\right)-\mathrm{D}_{\mathrm{i}}\left(\Delta \mathrm{T}_{\mathrm{t}}\right)-\left[1-\mu_{\mathrm{i}, \mathrm{t}}\right] \frac{\mathrm{C}_{\mathrm{i}}^{\prime}\left(\mu_{\mathrm{i}, \mathrm{t}}\right)}{\left[1+\rho_{\mathrm{i}}\right]^{\mathrm{t}}}\right\}-\delta_{\mathrm{K}}
$$

This condition is a modification of the standard Ramsey rule for optimal capital accumulation. Without climate change problem, condition (11) would simplify to $\rho_{\mathrm{i}}=\mathrm{F}_{\mathrm{i}, \mathrm{t}}{ }^{\prime}\left(\mathrm{K}_{\mathrm{i}, \mathrm{t}}\right)-\delta_{\mathrm{K}}$. That is, capital is allocated over time such that marginal productivity of capital (net of depreciation) is equal to the discount rate. In the presence of climate change externalities, this rule is modified, implying a downward adjustment of the marginal productivity since the term in curly brackets on the right-hand side of (11) is smaller than one. This implies a slower rate of capital accumulation, and ceteris paribus of output growth and carbon emissions.

Given the public "bad" nature of emissions, the economic strategies of countries are interdependent. Therefore, we have to solve simultaneously the two first order conditions for each country at each time $t$ for every coalition structure $c$. Since we assume complete information, the Nash equilibrium strategy vectors can be interpreted as open loop Nash equilibria. In order to calculate numerically Nash equilibria, we use a standard numerical algorithm proceeding interatively. The iteration process continues until the Euclidean distance between strategy vectors in two consecutive iterations is smaller than a given threshold value. 
For our data set we never encountered covergence problems and found always a unique equilibrium for each of the 203 possible coalition structures.

Note that our setting implies that if we move from some coalition structure $\mathrm{c}$ to any other coalition structure $c^{\prime}$, this means a change of strategies and affects welfare of countries (valuations). Thus if for instance two coalitions in coalition structure c merge, leading to coalition structure $\mathrm{c}^{\prime}$, they usually increase their abatement efforts but this may be matched by an expansions of emissions by countries not involved in this merger. The amount of these leakage effects depends on the particular coalition structure, on the parameters of the marginal damage and cost functions and on the physical parameters of the climate system.

As pointed out in section 2, we consider a scenario with transfers in which case $\hat{v}_{i}(c)=v_{i}(c)+t_{i}$. We adopt the transfer scheme used in Eyckmans and Tulkens (1999) which is a modification of the scheme proposed by Chander and Tulkens (1995 and 1997). The scheme assumes only transfers within coalitions where the surplus of a coalition $\mathrm{c}^{\mathrm{k}}$ from cooperation is allocated according to a proportional sharing rule:

$$
\mathrm{t}_{\mathrm{i}}=\left[\mathrm{v}_{\mathrm{i}}\left(\mathrm{c}^{\mathrm{N}}\right)-\mathrm{v}_{\mathrm{i}}(\mathrm{c})\right]+\lambda_{\mathrm{i}} \sum_{\mathrm{i} \in \mathrm{c}^{\mathrm{k}}}\left[\mathrm{v}_{\mathrm{i}}(\mathrm{c})-\mathrm{v}_{\mathrm{i}}\left(\mathrm{c}^{\mathrm{N}}\right)\right]
$$

where shares $\lambda_{i}$ are given by:

$$
\lambda_{\mathrm{i}}=\frac{\sum_{\mathrm{t}=0}^{\Omega} \frac{\mathrm{Y}_{\mathrm{i}, \mathrm{t}} \mathrm{D}_{\mathrm{i}}^{\prime}\left(\Delta \mathrm{T}_{\mathrm{t}}\right)}{\left[1+\rho_{\mathrm{i}}\right]^{\mathrm{t}}}}{\sum_{\mathrm{i} \in \mathrm{c}^{\mathrm{k}}} \sum_{\mathrm{t}=0}^{\Omega} \frac{\mathrm{Y}_{\mathrm{i}, \mathrm{t}} \mathrm{D}_{\mathrm{i}}^{\prime}\left(\Delta \mathrm{T}_{\mathrm{t}}\right)}{\left[1+\rho_{\mathrm{i}}\right]^{\mathrm{t}}}}
$$

The first term in big brackets in (12) sets every country back to its welfare level in the singleton coalition structure, the second term allocates the total surplus of coalition $\mathrm{c}^{\mathrm{k}}$ compared to the singleton coalition structure in proportion to their marginal damages. Hence, the second term in (12) favors countries with relatively high potential production and marginal damage estimates and low discount rates since they are entitled to a larger share of their coalition's aggregate payoff. However, the first term ensures that members which would loose from cooperation without transfers because they contribute much to joint abatement but benefit only little because of low marginal abatement and damage costs break at least even (provided there is a surplus from cooperation). Notice that if a coalition's surplus from joint cooperation is positive, then the transfer scheme ensures that every country receives a higher payoff than in the singleton coalition structure. Generally, there may be no surplus if leakage effects are strong enough, though for our data set it turns out that this is always the case. 


\subsection{Reference Simulations}

\section{Carbon emissions and atmospheric carbon concentrations}

Figure 1 shows annual world carbon emissions in three scenarios: business-as-usual (BAU), implying no emission reduction ( $\mu_{\mathrm{i}, \mathrm{t}}=0 \forall \mathrm{i}, \forall \mathrm{t}$ ), Nash equilibrium (NASH), corresponding to the singleton coalition structure, and social optimum, $\mathrm{SO}$, correponding to the grand coalition. ${ }^{8}$ We only consider carbon emissions originating from fossil fuel use where world carbon emissions in 1990 amount to approximately 6 gigatons of carbon. It is evident that BAU-emissions continuously grow, reach nearly $40 \mathrm{GtC}$ by the year 2100 , and more than $62 \mathrm{GtC}$ in 2200. BAU-emissions continue growing throughout the entire time horizon although the pace of growth gradually slows down. NASH-emissions grow at a slightly slower rate to reach about $38 \mathrm{GtC}$ by the year 2100 and $59 \mathrm{GtC}$ by 2200 . Also NASHemissions continue growing though growth decelerates. In contrast, SO-emissions are substantially lower: in 2100 they amount to roughly $24 \mathrm{GtC}$, and only $21 \mathrm{GtC}$ in 2200 . This is about half of NASH-emissions in 2100 and almost one third of NASH-emissions in 2200. In contrast to NASH-emissions, the SO-emission path rises until 2150, levels off at about $26 \mathrm{GtC}$ and decreases afterwards.

\section{FIGURE 1 and FIGURE 2 about here}

Figure 2 shows the atmospheric carbon concentration in the three scenarios. In 1990 atmospheric carbon concentration amounts to approximately $750 \mathrm{GtC}$. BAU-concentration rises steadily and reaches about $1718 \mathrm{GtC}$ in 2100 and $3443 \mathrm{GtC}$ in 2200 . Doubling of the concentration with respect to 1990 takes place between 2080 and 2090. The NASHconcentration path follows closely the BAU-path and continues to grow steadily over the entire time horizon. In contrast, SO-concentration grows at a much slower rate and reaches $1368 \mathrm{GtC}$ in 2100 and $2017 \mathrm{GtC}$ in 2200 . Doubling of atmospheric carbon concentration is postponed until some time between 2110 and 2120. The carbon concentration levels off at about 2000 GtC by the year 2200 .

At the level of individual countries there are substantial differences across regions. Taking averages of abatement efforts over time, we find in the Nash equilibrium that $C H N$ abates about $7.70 \%$, followed by $E U$ with $7.24 \%$ and $U S A$ with $6.44 \%$. The lowest abatement effort is undertaken by $R O W$ with only $1.45 \%$. World average abatement amounts to $3.74 \%$. For

8 All figures report data for a time horizon of 1990 to 2250 . However, all calculations were conduct for the entire time period of 350 years. 
ROW low abatement is due to strong free-rider incentives within this heterogeneous region. ${ }^{9}$ For $C H N$ high abatement is due to low marginal abatement costs and for $E U$ this is due to their high climate change damage valuation. In the social optimum world average abatement is $37.14 \%$. $C H N$ and $R O W$ are required to reduce their emissions substantially more than other regions (68.13\% and 55.50\%, respectively) due to their low marginal abatement costs.

\section{Macoreconomic Magnitutes}

Figures 3 and 4 show the time profiles of world consumption, Z, investment, I, abatement cost, YC, and damage costs, YD, for NASH- and SO-scenario where potential production, Y, is the sum of these components (see (1)). It is evident that production and consumption profiles are quite similar in both scenarios. The small differences in terms of production and consumption stem from the fact that abatement costs and damage costs consitute a small portion of total production and consumption. Hence, strong differences in the emission and concentration path in both scenarios do not alter much the production and consumption patterns and thus also not $\mathrm{YC}+\mathrm{YD}$. However, the composition of $\mathrm{YC}$ and $\mathrm{YD}$ is different in the two scenarios. In the Nash equilibrium abatement costs are very small (they do show up in Figure 3) but climate change damage are high. In contrast, in the social optimum damage costs are relatively small but this gain requires devoting part of the production to emission abatement.

\section{FIGURE 3 and FIGURE 4 about here}

Table 1 displays total discounted consumption $\mathrm{v}_{\mathrm{i}}(\mathrm{c})=\mathrm{w}_{\mathrm{i}}\left(\mathrm{s}^{*}\right)=\sum_{\mathrm{t}=0}^{\Omega} \mathrm{Z}_{\mathrm{i}, \mathrm{t}} /\left[1+\rho_{\mathrm{i}}\right]^{\mathrm{t}}$ for each region in the Nash equilibrium, $v_{i}^{N}=v_{i}\left(c^{N}\right)$, and in the social optimum, $v_{i}^{S}=v_{i}\left(c^{S}\right)$. The last row World reveals the overall magnitudes at stake. Discounted consumption amounts to 338,060 million $\$$ in the Nash equilibrium and 339,831 million \$ in the social optimum. Though the gain at the world level from full cooperation is not a small number, in relative terms it amounts to only $0.52 \%$. This is due three reasons. First, as pointed out above, abatement costs and climate change damages are small compared to production or consumption. Second, differences between both scenarios in terms of welfare occure mainly in the far future but receive less weight due discounting. Third, abatement costs are relatively high compared to the benefits from reduced emissions for greenhouse gases, so that also in

As in Nordhaus and Yang (1996) we have revised downward the climate change damage parameter of $R O W$ in all partitions in which $R O W$ is a singleton in order to account for the fact that this region comprise of many countries. 
the social optimum only moderate action is required. Nevertheless, as argued above, there are large differences between both scenarios in ecological terms.

Table 1: World Discounted Consumption*

\begin{tabular}{ccccccc}
\hline & $\mathrm{v}_{\mathrm{i}}^{\mathrm{N}}$ & $\mathrm{v}_{\mathrm{i}}^{\mathrm{S}}$ & $\left(\mathrm{v}_{\mathrm{i}}^{\mathrm{S}}-\mathrm{v}_{\mathrm{i}}^{\mathrm{N}}\right) / \mathrm{v}_{\mathrm{i}}^{\mathrm{S}}$ & $\mathrm{t}_{\mathrm{i}}$ & $\hat{\mathrm{v}}_{\mathrm{i}}^{\mathrm{S}}$ & $\left(\hat{\mathrm{v}}_{\mathrm{i}}^{\mathrm{S}}-\mathrm{v}_{\mathrm{i}}^{\mathrm{N}}\right) / \hat{\mathrm{v}}_{\mathrm{i}}^{\mathrm{S}}$ \\
\hline USA & 78,352 & 78,989 & +0.81 & -286 & 78,703 & +0.45 \\
JPN & 42,909 & 43,224 & +0.73 & -123 & 43,101 & +0.45 \\
EU & 102,730 & 103,654 & +0.89 & -429 & 103,225 & +0.48 \\
CHN & 9,140 & 8,856 & -3.21 & +338 & 9,194 & +0.59 \\
FSU & 23,794 & 24,025 & +0.96 & -124 & 23,901 & +0.45 \\
ROW & 81,135 & 81,083 & -0.06 & +624 & 81,707 & +0.70 \\
\hline WORLD & $\mathbf{3 3 8 , 0 6 0}$ & $\mathbf{3 3 9 , 8 3 1}$ & $\mathbf{+ 0 . 5 2}$ & $\mathbf{0}$ & $\mathbf{3 3 9 , 8 3 1}$ & $+\mathbf{0 . 5 2}$ \\
\hline
\end{tabular}

* Figures are the discounted sum of consumption in million US\$ $\$_{1990}$. All variables as explained in the text.

In terms of individual winners and loosers, we find that $C H N$ and, to a lesser extent, $R O W$ would lose from full cooperation without transfers. ${ }^{10}$ With transfer individual rationality holds for all countries in the social optimum and as mentioned above for any other coalition structure different from the grand coalitions for our data set as well. Hence, without transfers the grand coalition cannot be an equilibrium in any of the coalition formation games defined in section 2 . However, individual rationality is only a necessary condition for stability and as we will see from section 4 by no means sufficient to guarantee stability.

\section{Stability Analysis}

In this section we report on results of our stability analysis in the three coalition formation games. In subsection 4.1 we explain the information contained in Table 2 and 3, summarizing our results. In subsection 4.2 we provide some rationale that helps to explain membership in stable coalitions and in subsection 4.3 we evaluate and compare stable coalition structures in the three coalition formation games.

\subsection{Information in Table 2 and 3}

Table 2 and 3 list stable coalition structures in the no transfer and transfer case, respectively. The first column lists the number of a particular coalition structure where to each coalition structure a number between 1 and 203 is attached. Coalition structure 1 represents the singleton coalition structure, corresponding to the "conventional" Nash equilibrium, whereas coalition structure 203 is the grand coalition, corresponding to the "conventional" social

10 A more detailed analysis of the incentive to cooperate is provided in subsection 4.2. 
optimum. Apart from stable coalition structures, these coalition structures are listed because they represent benchmarks. Column 2 lists coalition structures in partition form where nontrivial coalitions are indicated bold. Column 3,4 and 5 contain information whether a coalition is stable in a coalition game ( $\mathrm{n}=$ not stable, $\mathrm{y}=$ stable). We list only those coalition structures that are stable and Pareto-undominated by any other stable coalition structure in at least one game. For instance, in the transfer case (Table 3), there are 34 stable coalition structures in the exclusive membership game (EMG) of which 19 are Pareto-dominated by other stable coalition structures and none of them is stable in the open membership games (OMG and ROMG). Hence, only 15 coalition structures are listed in Table 3. Since some of these coalition structures are Pareto-dominated in the EMG but not in the ROMG, Paretodomination is indicated by a gray cell.

\section{TABLE 2 and 3 about here}

Column 6 gives total discounted welfare over all regions and the entire time period (19902330). We take this feature to sort coalition structures in descending order. Column 9 gives concentration at the end of the time period and column 12 indicates total emissions over all regions and the entire time period. In order to evaluate coalition structures, we compute two indices. The first index is called the "degree of externality index" (DEX). This index measures the relative differences between the outcome in a coalition structure (superscript $\mathrm{C}$ ) and the social optimum (superscript $\mathrm{S}$ ) and is defined as follows:

welfare: $100 \cdot\left(\frac{\sum_{i=1}^{N} v_{i}\left(c^{S}\right)-\sum_{i=1}^{N} v_{i}(c)}{\sum_{i=1}^{N} v_{i}\left(c^{S}\right)}\right)$, concentration: $100 \cdot\left(\frac{M_{\Omega}^{C}-M_{\Omega}^{S}}{M_{\Omega}^{S}}\right)$

emission: $100 \cdot\left(\frac{\sum_{\mathrm{t}=0}^{\Omega} \sum_{\mathrm{i}=1}^{\mathrm{N}} \mathrm{E}_{\mathrm{i}, \mathrm{t}}^{\mathrm{C}}-\sum_{\mathrm{t}=0}^{\Omega} \sum_{\mathrm{i}=1}^{\mathrm{N}} \mathrm{E}_{\mathrm{i}, \mathrm{t}}^{\mathrm{S}}}{\sum_{\mathrm{t}=0}^{\Omega} \sum_{\mathrm{i}=1}^{\mathrm{N}} \mathrm{E}_{\mathrm{i}, \mathrm{t}}^{\mathrm{S}}}\right)$

where all variables are those of section 3. By definition, in the social optimum the degree of externality is 0 . The second index is called the "closing the gap index" (CGX). This index measures the difference between the outcome in a coalition structure and the social optimum in relation to the difference between the Nash equilibrium and the social optimum. It is defined as $100 \cdot\left(1-\mathrm{DEX}^{\mathrm{C}} / \mathrm{DEX}^{\mathrm{N}}\right)$ where the superscript $\mathrm{N}$ stand for Nash equilibrium. Thus, by definition, this index is 100 in the social optimum and 0 in the Nash equilibrium. All numbers have been rounded to "sensible" digits for interpretation. 


\subsection{Rationalizing Membership in Stable Coalition Structures}

From a first glance at the tables one is let to conjecture that intuition is not confirmed by the results: many coalitions of stable coalition structures comprise countries of which one would expect that they should show little interest in forming a coalition and/or not with those countries listed in Table 2 and 3. For instance, it may be suspected that "rest of the world" (ROW) should show little interest in participating in an agreement and that USA and ROW will hardly be in one coalition because of different interests. However, a closer look at the underlying fundamentals resolves this puzzle though it is difficult to trace all effects in a general equilibrium model. First, climate change damage parameters in our model are modified estimates of RICE that may not be in line with the presumed perception of damages in a country. For instance, it has been argued that developing countries will pay little attention to environmental damages due to strong preferences for economic growth. This would suggest for instance that the damage costs of ROW should be very low, though in our model they are relatively high, despite we assume higher discount rates for ROW and $\mathrm{CHN}$ than for the rest of the countries (see Appendix). Second, the conjecture that countries forming a coalition with other countries are the "good guys" and countries remaining singletons are the "bad guys" is premature. This conjecture presumes that coalition members will substantially reduce their emissions compared to the non-cooperative benchmark and compared to outsiders. However, this is not always the case for at least two reasons. One reason is that if for instance two countries form a coalition where both countries face high marginal abatement costs and low marginal damages costs, then joint welfare maximization implies only a marginal reduction compared to the non-cooperative benchmark. In contrast, a singleton with low marginal abatement costs and high marginal damage costs may reduce emissions substantially by itself. A second reason is that due to non-cooperative behavior and externalities across coalitions, leakage effects may lead to downgraded abatement efforts in equilibrium (as derived from the valuation function). Taken together, there may well be stable "coalitions of the lazy guys". Third, the incentive to form a stable coalition follows from a subtle incentive structure. In order to shed some light on the fundamentals, we construct two indices that are based on two values. The first value aims at measuring the interest of a country in climate change policy in terms of benefits. For this we compute discounted marginal damages in the Nash equilibrium for each country and evaluate those numbers in relative terms (ROW=100\%). From Table 4 it is evident that - neglecting abatement costs - EU and ROW have the highest and CHN the lowest interest in reducing greenhouse gases. The second value aims at measuring the interest of a country in cooperation in terms of abatement contributions. As follows from the first order condition in (10), countries with low marginal abatement cost will have to contribute 
more to joint abatement than those with high marginal abatement costs. Since it turns out for our data set that marginal abatement cost curves never intersect, we can compute emission reductions for an arbitrary fixed tax rate. We choose a uniform tax rate of 20 US\$ per ton of carbon in each period. Again, we evaluate emission reductions in relative terms and compute average relative contributions for the entire time period $(\mathrm{CHN}=100 \%)$. From Table 4 it is evident that $\mathrm{CHN}$ and ROW have to make the highest contributions due to their low marginal abatement costs. In order to depict the entire incentive structure, we compute a free-rider index 1 in row 3 that is defined as abatement contribution (row 2) divided by marginal damages (row 1), evaluated in relative terms $(\mathrm{CHN}=100 \%$ ). Free-rider index 2 (row 4) ranks these numbers that makes subsequent interpretation easier. From Table 4 it is evident that $\mathrm{CHN}$ has by far the highest free-rider incentive. That is, $\mathrm{CHN}$ has to contribute very much to a joint abatement policy but benefits only little from reduced damage costs. The opposite incentive structure is that of the EU: she contributes less on average to cooperation but benefits more than proportionally from reduced damages.

Table 4: Incentive Index of Coalition Formation

\begin{tabular}{|l|l|c|c|c|c|c|c|}
\hline & & USA & JPN & EU & CHN & FSU & ROW \\
\hline 1 & marginal damages & 64 & 35 & 91 & 10 & 21 & 100 \\
\hline 2 & abatement contribution & 25 & 21 & 23 & 100 & 29 & 79 \\
\hline 3 & free-rider index 1 & 3.9 & 6.0 & 2.5 & 100.0 & 10.4 & 7.9 \\
\hline 4 & free-rider index 2 & 2 & 3 & 1 & 6 & 5 & 4 \\
\hline
\end{tabular}

For the interpretation of the free-rider indices three remarks are in order. 1) The indices can only be a crude measure since it represents only an "average incentive structure" that generally differs from those in particular coalition structures. 2) Though it is certainly true that a high free-rider index indicates that a country has no interest in forming a coalition, not only the absolute value is important but the relative distance between those values. That is, countries with a high but similar index may well form a coalition because of similar interests as this is the case for instance for FSU and ROW in coalition structure 153 in Table 2. 3) The indices can only be used in the case of no transfers since transfers may imply a substantial redistribution of welfare so that also high free-rider index countries can have an incentive to form a coalition.

Keeping these caveats in mind, we can now try to rationalize membership of some stable coalition structures listed in Table 2 and 3. Without transfers (Table 2) it is evident that CHN 
is never a member of a stable coalition because of its strong free-rider incentive. Also EU is only a coalition member in one stable coalition structure (No. 155) since countries have usually no interest forming a coalition with EU because of her high marginal damages. This would require substantial emissions reductions by coalition partners combined with little contribution of EU to joint efforts. The only exception is a coalition with ROW in coalition structure No. 155 since ROW faces even higher marginal damages than the EU. Coalition structures which demonstrate that countries with similar interests form a coalition are for instance No. 26, 156, 20, 6, 153 and 5. ${ }^{11}$

In the case of transfers the picture is different. Now, $\mathrm{CHN}$ is a frequent member in coalitions within stable coalition structures; in particular in coalitions with the USA, EU and ROW. Those countries have marginal damages above average and therefore have an interest in ambitious emission reductions. Due to high marginal abatement costs, they benefit from cheap emission reduction of CHN. CHN's interest in participation stems from the fact that it it is compensated for its high contribution and receives a fair amount of the suplus from cooperation. Taken together, transfers balance different interests and thus allow to reap efficiency gains from cooperation between unequal partners.

\subsection{Evaluating and Comparing Stable Coalition Structures}

\section{General comments}

The grand coalition is not stable in the sense of definition 5. In the no transfer case this follows immediately from the fact that $\mathrm{CHN}$ and ROW are worse off than in the singleton coalition structure (see Table 1). However, individual rationality is only a necessary but not a sufficient condition for stability. Hence, also in the case of transfers, the grand coalition is not stable. In fact, only coalition structures comprising small coalitions with no more than three members are stable. The reason is that the incentive to leave a coalition increases with the number of coalition members. Nevertheless, also agreements with only few countries can close the gap between first best and no cooperation by a substantial amount. For instance, in the EMG the stable coalition structure associate with the highest global welfare closes the gap between Nash equilibrium and social optimum by 60.7 and 74.5 percent in the case of no transfers and transfers, respectively, though this percentages are lower for concentration and emissions. However, also the degrees of externality for concentration (138 \%) and emissions

11 Using free-rider incentive index 2 we find: $26:\{2,5,4\}, 156:\{2,3,4\}, 20:\{3,5,4\}, 6:\{2,4\}$, 153: $\{2,3\},\{5,4\}$ and $5:\{3,4\}$ where the values are index numbers of coalition members in these coalition structures. 
(106\%) are substantially higher than for welfare in the Nash equilibrium so that a 50 percentage reduction of externalities in a stable coalition structure may be judged as a success. Interestingly, the "degree of cooperation" is not necessarily an indicator for success as is evident from comparing coalition structure No. 133 (three coalitions of two countries) and coalition structures No. 63 to 64 (only two coalitions of two countries) in the case of transfers.

The empirical findings are perfectly in line with the theoretical findings of non-cooperative coalition theory, applying the concept of internal\&external stability (see Introduction and Finus 2003). First, the number of participants or the degree of cooperation is not an indication of the success of coalition formation. Second, whenever the degree of externality is low, only small coalitions are stable but they achieve much and if the degree is high the opposite holds. In our context this degree is small in welfare terms (though admittedly it is larger in ecological variables) since abatement costs are relatively high compared to the benefits from reduced damages. As Barrett (1994) pointed out, this relation may be reversed for CFCs, predicting large coalitions but less success for solving the problem of the depletion of the ozone layer effectively. In this light, the current Kyoto Protocol may be seen less pessimistic despite its rather low participation.

\section{Open versus exclusive membership}

In the OMG no coalition structure is stable. The assumption of unrestricted accession to any coalition causes great instability. This is similar in the ROMG, though singletons cannot be joined without their consent. Hence, the problem of instability is mitigated to some extent and hence five coalition structures are stable in the case of transfers. The fact that the singleton coalition structure is stable in the ROMG follows from the definition of this game. If each country announces address 0 , then a single deviation cannot lead to a different coalition structure and hence a simultaneous announcement of strategy $\sigma_{i}=0$ by all countries is trivially a Nash equilibrium coalition structure. ${ }^{12}$ From an theoretical point of view this may be regarded as an advantage since it guarantees existence of an equilibrium. From an applied point of view this may be perceived as disturbing. Why should the singleton coalition structure be considered as stable if two or more countries have an incentive to form a coalition? However, this apparent shortcoming is removed by our stronger definition of Pareto-undominated stability. In this sense, the singleton coalition structure is not stable in the transfer case but is stable in the no transfer case because no other stable coalition structure

\footnotetext{
12 A similar argument establishes that the singleton coalition structure is always a Nash equilibrium coalition structure in the EMG.
} 
exists. Thus, not only our argument developed in section 2 that ROMG better captures features of actual international environmental treaty formation supports the superiority of the ROMG over the OMG but also our empirical applications.

A comparison between stable coalition structures in the ROMG and the EMG reveals three features. First, trivially, the theoretical prediction that any coalition structure that is stable in the ROMG is also stable in the EMG but not vice versa is confirmed. Second, more interesting, there are far more stable coalition structures in the EMG than in the ROMG. For instance, in the no transfer case no non-trivial stable coalition structure exists in the ROMG whereas in the EMG there are seven Pareto-undominated stable coalition structures. Third, some of the additional stable coalition structures in the EMG compared to the ROMG are superior in terms of welfare, concentration and emissions. For instance, in the case of transfers there are two stable coalition structures in the EMG (No. 63 and 31) that are superior to that stable coalition structure, which produces the highest global welfare as well as the lowest concentration and emissions in the ROMG (No. 46). Thus, we can conclude that exclusive membership is conducive to stability and efficient cooperation.

From a theoretical point of view the results are interesting since internal \& external stability as applied in previous work in non-cooperative coalition theory de facto implies open membership. From an applied point of view, the results are interesting in two respects. First, almost all past IEAs have no provision to restrict membership. Hence, it may be worthwhile to think whether to adopt an exclusive membership rule, which is typical for club good agreements as for instance NATO and European Union, also for public good agreements like those on climate change in the future. Second, exclusive membership also requires some degree of unanimity between coalition partners to form a coalition. Thus, though it is usually argued that the need for consensus within international organization and governments implies that only less ambitious policies (of the least common denominator type) can be implemented, in the present context consensus is conducive to cooperation.

\section{No transfers versus transfers}

Tables 2 and 3 reveal that the first nine stable coalition structures in the EMG in the case of transfers (No. 63 to 133) are superior to the coalition structure with the highest welfare in the case of no transfers (No. 26). Thus, the conjecture is confirmed that transfers are an important tool to increase participation and the success of stable agreements. Nevertheless, also transfers cannot totally overcome free-rider incentives and hence stable coalition structures comprise 
only small coalitions and welfare is below, and concentration and emissions above globally optimal levels.

The results are line with almost all theoretical and empirical findings of coalition models that show that transfers lead to superior outcomes (see the literature discussed and cited in Finus 2003). The results also support efforts within recent IEAs, like the Montreal and Kyoto Protocol, to establish multilateral funds that compensate developing countries for cooperation.

\section{Multiple versus single coalitions}

In the transfer case all coalition structures of higher ranks in terms of global welfare that are stable in the EMG comprise of multiple coalitions. In the case of no transfers there are also two stable coalition structures with multiple coalitions. This suggests that not only will countries form multiple agreements if coalition formation is not restricted to a single coalition but also that multiple may be superior to single agreements from a global point of view. Due to strong incentives to leave a coalition (or to remain a singleton) those multiple coalitions are not necessarily large than single coalitions (and in fact they are not), but some countries decide to form their own agreement instead of remaining without any partner. The intuition is that it is easier to guarantee stability in small coalitions with members of similar interests than in large coalitions that automatically imply a larger degree of heterogeneity.

From a theoretical point of view, the results suggest that restricting coalition formation exogenously to a single coalition as implied by internal \& external stability may lead to wrong conclusions. From an applied point of view, results are somehow puzzling since the record of past IEAs suggests that countries form only single agreements. This leads us to two controversial conjectures. First, if existing IEAs are the result of an unrestricted coalition formation process, then our predictions would be wrong. One reason may be that our results are derived from a stylized model of coalition formation and that parameter assumptions do not reflect the "true" incentive structure. However, it has to be pointed out that our main conclusion from above is very robust to different specifications of parameter values and has also be tested for other coalition games. ${ }^{13}$ Second, if coalition formation has been restricted for institutional and/or political reasons in the past, this suggests altering the rules in the future. For instance, under the Kyoto Protocol the USA insisted for a long time before it dropped out that they would only ratify the treaty if also developing countries would accede to this agreement. Thus, it may be the case that more could have been achieved if separate agreements were designed for industrialized countries, developing countries and countries in

13 Results of sensitivity analyses are available upon request from the authors. 
transition. This last remark points at the possibility to reconcile both conjectures. Taking a broader perspective, some modern IEAs, as for instance the Kyoto and Montreal Protocol, may be interpreted as separate agreements under the umbrella of one treaty since they impose differentiated abatement obligations on participants. In any case, our results support the philosophy of different responsibilities of "modern" IEAs that contrast with "old" IEAs, frequently specifying abatement obligations in terms of uniform emissions reductions (see Finus 2003 on empirical evidence).

\section{Summary and Final Remarks}

We modeled coalition formation in international climate change control as a two stage game: countries decide in the first stage on their membership in a coalition and in the second stage coalition members choose their economic strategies. For the first stage we considered three coalition games that represent three different rules how coalition form: open membership, restricted open membership and exclusive membership. In the second stage we assumed that coalition members jointly chose abatement and capital investment strategies as to maximize the aggregate welfare to their coalition. Based on an empirical computable general equilibrium model that captures a time horizon of 350 years we computed payoff vectors (valuations) for six world regions and for each possible coalition structure. For each coalition game we computed stable (equilibrium) coalition structures and evaluated them in terms of global welfare, concentration and total emissions. From the many results we would like to mention four. 1) Stable coalition structures comprise of coalitions with only a few members. Nevertheless, in the context of climate change those stable coalition structures can close the gap between no cooperation and full cooperation to a large extent. Thus, "small may be beautiful (or least not that ugly)"! 2) Under exclusive membership more coalition structures are stable than under open and restricted open membership that are also superior in welfare and ecological terms. We suggested to consider changing the open access rule of most IEAs to restricted access in future IEAs as implied by most club good agreements. Moreover, the results indicate that the need for consensus in international politics may not always hamper, but, in fact, may be conducive for the implementation of ambitious abatement policies. 3) Without transfers countries with a similar incentive structure in terms of marginal abatement and damage costs form coalitions. Countries with either low or high marginal abatement and damage costs will usually not participate in cooperation since they do not find "equally-minded" partners. With transfer contrasting interests can be balanced that allows to reap efficiency gains from cooperation. The result support the efforts in recent IEAs like the Kyoto and Montreal Protocol to raise participation of developing countries with low marginal 
abatement costs via compensation payments. 4) Many stable coalition structures comprise of multiple coalitions that are superior to single coalitions in welfare and ecological terms. The reason is that it is difficult to form one large coalition because of strong free-rider incentives but it is easier to form several small coalitions because interests within a coalition are more homogeneous. This suggests not to pursue a strategy to get as many countries into "one climate boat" in future treaties but to allow for differentiation of abatement targets and/or regional agreements.

For future research we would like to mention three (of certainly many possible) extensions. First, other transfer schemes than the Chander/Tulkens' transfer rule that we considered could be analyzed. The purpose of this exercise would be to find an "optimal transfer scheme" that allows - in the face of heterogeneous interests - for stable coalition structures generating high global welfare. Second, and closely related to the first point, the effect of different permit trading schemes on coalition formation could be analyzed. Third, stable coalition structures could be determined for other coalition formation games. These coalition games could be different in terms of the design of protocols (e.g., Carraro, Marchiori and Oreffice 2001 and Finus and Rundshagen 2003), could capture the feature of a minimum participation that is a typical requirement in many IEAs before a treaty becomes binding for all participants (Black, Levi and de Meza 1992), and could model coalition formation as a sequential process with initiators and follower that may capture closer actual treaty formation (Finus/Rundhagen 2001b).

\section{References}

Barrett, S. (1994), Self-Enforcing International Environmental Agreements. "Oxford Economic Papers", vol. 46, pp. 804-878.

Barrett, S. (1997), Heterogeneous International Agreements. In: C. Carraro (ed.), International Environmental Negotiations: Strategic Policy Issues. Edward Elgar, Cheltenham, pp. 9-25.

Barrett, S. (1998), On the Theory and Diplomacy of Environmental Treaty-Making. "Environmental and Resource Economics", vol. 11, pp. 317-333.

Barrett, S. (2000), Consensus Treaties. Preliminary Draft, Johns Hopkins University, Washington D.C.

Black, J., M. D. Levi and D. de Meza (1992), Creating a Good Atmosphere: Minimum Participation for Tackling the "Greenhouse Effect". "Economica", vol. 60, pp. 281-293.

Bloch, F. (1997), Non-Cooperative Models of Coalition Formation in Games with Spillovers. In: Carraro, C. and D. Siniscalco (eds.), New Directions in the Economic Theory of the Environment. Cambridge University Press, Cambridge, ch. 10, pp. 311-352. 
Bohm, P. (1993), Incomplete International Cooperation to Reduce $\mathrm{CO}_{2}$ Emissions: Alternative Policies. "Journal of Environmental Economics and Management", vol. 24, pp. 258271.

Botteon, M. and C. Carraro (1997), Burden-Sharing and Coalition Stability in Environmental Negotiations with Asymmetric Countries. In: Carraro, C. (ed.), International Environmental Negotiations: Strategic Policy Issues. Edward Elgar, Cheltenham et al., ch. 3, pp. 26-55.

Carraro, C., C. Marchiori and S. Oreffice (2001) Endogenous Minimum Participation in International Environmental Treaties. Mimeo, Fondazione Eni Enrico Mattei.

Carraro, C. and D. Siniscalco (1993), Strategies for the International Protection of the Environment. "Journal of Public Economics", vol. 52, pp. 309-328.

Chander, P. and H. Tulkens (1995), A Core-Theoretic Solution for the Design of Cooperative Agreements on Transfrontier Pollution. "International Tax and Public Finance", vol. 2, pp. 279-293.

Chander, P. and H. Tulkens (1997), The Core of an Economy with Multilateral Environmental Externalities. "International Journal of Game Theory", vol. 26, pp. 379-401.

Chichilnisky, G. and G. Heal (1994), Who Should Abate Carbon Emissions: an International View. "Economic Letters", vol. 44, pp. 443-449.

d'Arge, R.C., W. D. Schulze and D.S. Brookshire (1982), Carbon Dioxide and Intergenerational Choice. "American Economic Review", vol. 72, pp. 251-256.

Ecchia, G. and M. Mariotti (1998), Coalition Formation in International Environmental Agreements and the Role of Institutions. "European Economic Review", vol. 42, pp. 573582.

Eyckmans, J., S. Proost, and E. Schokkaert (1993), Equity and Efficiency in Greenhouse Negotiations. "Kyklos", vol. 46, pp. 363-397.

Eyckmans, J. (2001), On the Farsighted Stability of the Kyoto Protocol. Working Paper Series, Faculty of Economics and Applied Economic Sciences, University of Leuven, No. 2001-03.

Eyckmans, J. and H. Tulkens (1999), Simulating with RICE Coalitionally Stable Burden Sharing Agreements for the Climate Change Problem. CES ifo Working Papers Series, No. 228, Munich.

Finus, M. (2001), Game Theory and International Environmental Cooperation. Edward Elgar, Cheltenham.

Finus, M. (2002), New Developments in Coalition Theory: An Application to the Case of Global Pollution. Forthcoming in Rauscher, M. (ed.), "The International Dimension of Environmental Policy", Kluwer, Dordrecht, Holland.

Finus, M. (2003), Stability and Design of International Environmental Agreements: The Case of Transboundary Pollution. Forthcoming in Folmer, H. and T. Tietenberg (eds), International Yearbook of Environmental and Resource Economics, 2003/4, Edward Elgar, Cheltenham, UK. 
Finus, M. and B. Rundshagen (1998a), Toward a Positive Theory of Coalition Formation and Endogenous Instrumental Choice in Global Pollution Control. "Public Choice", vol. 96, pp. 145-186.

Finus, M. and B. Rundshagen (1998b), Renegotiation-Proof Equilibria in a Global Emission Game When Players Are Impatient. "Environmental and Resource Economics", vol. 12, pp. 275-306.

Finus, M. and B. Rundshagen (2001a), Endogenous Coalition Formation in Global Pollution Control. A Partition Function Approach. Working Paper No. 307, University of Hagen. Revised version forthcoming in Carraro, C. (ed.), Endogenous Formation of Economic Coalitions, Edward Elgar, Cheltenham, UK.

Finus, M. and B. Rundshagen (2001b), Sequential Move Unanimity Equilibria in a Public Good Model. Working Paper No. 308, University of Hagen.

Finus, M. and B. Rundshagen (2003), How the Rules of Coalition Formation Affect Stability of International Environmental Agreements. Preliminary Draft, University of Hagen.

Finus, M. and S. Tjøtta (2002), The Oslo Protocol on Sulfur Reduction: The Great Leap Forward? "Journal of Public Economics", forthcoming.

Germain, M., P. L. Toint and H. Tulkens (1998), Financial Transfers to Sustain Cooperative International Optimality in Stock Pollutant Abatement. In: Faucheux, S., J. Gowdy and I. Nicolai (eds), Sustainability and Firms: Technological Change and the Changing Regulatory Environment. Edward Elgar, Cheltenham, UK, ch. 11, pp. 205-219.

Germain, M., P. L. Toint, H. Tulkens and A. de Zeeuw (2000), Transfers to Sustain CoreTheoretic Cooperation in International Stock Pollutant Control. Revised version of CORE Discussion Paper No. 9832, Center for Operations Research and Econometrics, Université Catholique de Louvain, Louvain.

Hart, S. and M. Kurz (1983), Endogenous Formation of Coalitions. "Econometrica", vol. 51, pp. 1047-1064.

Hoel, M. (1992), International Environment Conventions: The Case of Uniform Reductions of Emissions. "Environmental and Resource Economics", vol. 2, pp. 141-159.

Hoel, M. (1994), Efficient Climate Policy in the Presence of Free Riders. "Journal of Environmental Economics and Management", vol. 27, pp. 259-274.

Hoel, M. and K. Schneider (1997), Incentives to Participate in an International Environmental Agreement. "Environmental and Resource Economics", vol. 9, pp. 153-170.

IPCC (2001), Climate Change 2001: Mitigation. Contribution of Working Group III to the Third Assessment Report of the Intergovernmental Panel on Climate Change, Cambridge: Cambridge University Press.

Kaitala, V., K.-G. Mäler and H. Tulkens (1995), The Acid Rain Game as a Resource Allocation Process with an Application to the International Cooperation among Finland, Russia and Estonia. "Scandinavian Journal of Economics", vol. 97, pp. 325-343. 
Nordhaus, W.D. (1991), To Slow or Not to Slow: the Economics of the Greenhouse Effect. "Economic Journal", vol. 101, pp. 920-937.

Nordhaus, W.D. and Z. Yang (1996), A Regional Dynamic General-equilibrium Model of Alternative Climate-change Strategies. "American Economic Review", vol. 86, pp. 741-765.

Rubio, S. and A. Ulph (2001), A Simple Dynamic Model of International Environmental Agreements with a Stock Pollutant. Preliminary Version, University of Southampton.

Rundshagen, B. (2002), On the Formalization of Open Membership in Coalition Formation Games. Working Paper No. 318, University of Hagen.

Stähler, F. (1996), Reflections on Multilateral Environmental Agreements. In: Xepapadeas, A. (ed.), Economic Policy for the Environment and Natural Resources: Techniques for the Management and Control of Pollution. Edward Elgar, Cheltenham and Brookfield, ch. 8, pp. 174-196.

Tol, R. (2001), Climate Coalitions in an Integrated Assessment Model. "Computational Economics", vol. 18, pp. 159-172.

Tol, R.S.J. (2002a), New Estimates of the Damage Costs of Climate Change, Part I: Benchmark Estimates. "Environmental and Resource Economics", vol. 21, pp. 47-73.

Tol, R.S.J. (2002b), New Estimates of the Damage Costs of Climate Change, Part II: Dynamic Estimates. "Environmental and Resource Economics", vol. 21, pp. 135-160.

Weyant, J. (ed.) (1999), The Costs of the Kyoto Protocol: a Multi-model Evaluation. "The Energy Journal", special issue.

Yi, S.-S. (1997), Stable Coalition Structures with Externalities. "Games and Economic Behavior", vol. 20, pp. 201-237.

Yi, S.-S. and H. Shin (1995), Endogenous Formation of Coalitions in Oligopoly. Mimeo, Department of Economics, Dartmouth College. 


\section{Appendix}

The CLIMNEG World Simulation Model comprises the following equations:

$$
\begin{aligned}
\mathrm{Y}_{\mathrm{i}, \mathrm{t}} & =\mathrm{Z}_{\mathrm{i}, \mathrm{t}}+\mathrm{I}_{\mathrm{i}, \mathrm{t}}+\mathrm{Y}_{\mathrm{i}, \mathrm{t}} \mathrm{C}_{\mathrm{i}}\left(\mu_{\mathrm{i}, \mathrm{t}}\right)+\mathrm{Y}_{\mathrm{i}, \mathrm{t}} \mathrm{D}_{\mathrm{i}}\left(\Delta \mathrm{T}_{\mathrm{t}}\right) \\
\mathrm{Y}_{\mathrm{i}, \mathrm{t}} & =\mathrm{a}_{\mathrm{i}, \mathrm{t}} \mathrm{K}_{\mathrm{i}, \mathrm{t}}^{\gamma} \mathrm{L}_{\mathrm{i}, \mathrm{t}}^{1-\gamma} \\
\mathrm{C}_{\mathrm{i}}\left(\mu_{\mathrm{i}, \mathrm{t}}\right) & =\mathrm{b}_{\mathrm{i}, 1} \mu_{\mathrm{i}, \mathrm{t}}^{\mathrm{b}_{\mathrm{i}, 2}} \\
\mathrm{D}_{\mathrm{i}}\left(\Delta \mathrm{T}_{\mathrm{t}}\right) & =\theta_{\mathrm{i}, \mathrm{t}} \Delta \mathrm{T}_{\mathrm{i}, \mathrm{t}}^{\theta_{\mathrm{i}}} \\
\mathrm{K}_{\mathrm{i}, \mathrm{t}+\mathrm{t}} & =\left[1-\delta_{\mathrm{K}}\right] \mathrm{K}_{\mathrm{i}, \mathrm{t}}+\mathrm{I}_{\mathrm{i}, \mathrm{t}} \quad \mathrm{K}_{\mathrm{i}, 0} \text { given } \\
\mathrm{E}_{\mathrm{i}, \mathrm{t}} & =\alpha_{\mathrm{i}, \mathrm{t}}\left[1-\mu_{\mathrm{i}, \mathrm{t}}\right] \mathrm{Y}_{\mathrm{i}, \mathrm{t}} \\
\mathrm{M}_{\mathrm{t}+1} & =\left[1-\delta_{\mathrm{M}}\right] \mathrm{M}_{\mathrm{t}}+\beta \sum_{\mathrm{i} \in \mathrm{N}} \mathrm{E}_{\mathrm{i}, \mathrm{t}} \quad \mathrm{M}_{0} \text { given } \\
\mathrm{F}_{\mathrm{t}} & =\frac{4.1 \ln \left(\mathrm{M}_{\mathrm{t}} / \mathrm{M}_{0}\right)}{\ln (2)}+\mathrm{F}_{\mathrm{t}}^{\mathrm{x}} \\
\mathrm{T}_{\mathrm{t}}^{0} & =\mathrm{T}_{\mathrm{t}-1}^{0}+\tau_{3}\left[\mathrm{~T}_{\mathrm{t}-1}^{\mathrm{a}}-\mathrm{T}_{\mathrm{t}-1}^{0}\right] \\
\mathrm{T}_{\mathrm{t}}^{\mathrm{a}} & =\mathrm{T}_{\mathrm{t}-1}^{\mathrm{a}}+\tau_{1}\left[\mathrm{~F}_{\mathrm{t}}-\lambda \mathrm{T}_{\mathrm{t}-1}^{\mathrm{a}}\right]-\tau_{2}\left[\mathrm{~T}_{\mathrm{t}-1}^{\mathrm{a}}-\mathrm{T}_{\mathrm{t}-1}^{0}\right] \\
\Delta \mathrm{T}_{\mathrm{t}} & =\frac{\mathrm{T}_{\mathrm{t}}^{\mathrm{a}}}{2.50}
\end{aligned}
$$

\section{List of Variables}

$\mathrm{Y}_{\mathrm{i}, \mathrm{t}} \quad$ production (billion 1990 US\$)

$\mathrm{Z}_{\mathrm{i}, \mathrm{t}} \quad$ consumption (billion 1990 US\$)

$\mathrm{I}_{\mathrm{i}, \mathrm{t}} \quad$ investment (billion 1990 US\$)

$\mathrm{K}_{\mathrm{i}, \mathrm{t}} \quad$ capital stock (billion 1990 US\$)

$\mathrm{C}_{\mathrm{i}, \mathrm{t}} \quad$ cost of abatement (billion 1990 US\$)

$\mathrm{D}_{\mathrm{i}, \mathrm{t}} \quad$ damage from climate change (billion 1990 US\$)

$\mathrm{E}_{\mathrm{i}, \mathrm{t}} \quad$ carbon emissions (billion tons of $\mathrm{C}$ )

$\mu_{\mathrm{i}, \mathrm{t}} \quad$ emission abatement

$\mathrm{M}_{\mathrm{t}} \quad$ atmospheric carbon concentration (billion tons of C)

$\mathrm{F}_{\mathrm{t}} \quad$ radiative forcing (Watt per $\mathrm{m}^{2}$ )

$\mathrm{F}_{\mathrm{t}}^{\mathrm{x}} \quad$ exogenous radiative forcing (Watt per $\mathrm{m}^{2}$ )

$\mathrm{T}_{\mathrm{t}}^{\mathrm{a}} \quad$ temperature increase in the atmosphere $\left({ }^{\circ} \mathrm{C}\right)$

$\mathrm{T}_{\mathrm{t}}^{0} \quad$ temperature increase in the deep ocean $\left({ }^{\circ} \mathrm{C}\right)$

$\Delta \mathrm{T}_{\mathrm{t}} \quad$ change of temperature increase in the atmosphere $\left({ }^{\circ} \mathrm{C}\right)$ 
Global Parameter Values

\begin{tabular}{llr}
\hline $\mathrm{a}_{\mathrm{i}, \mathrm{t}}$ & productivity & $\mathrm{RICE}$ \\
$\mathrm{L}_{\mathrm{i}, \mathrm{t}}$ & population & RICE \\
$\alpha_{\mathrm{i}, \mathrm{t}}$ & emission-output rate & $\mathrm{RICE}$ \\
$\delta_{\mathrm{K}}$ & capital depreciation rate & 0.10 \\
$\gamma$ & capital productivity parameter & 0.25 \\
$\beta$ & airborne fraction of carbon emissions & 0.64 \\
$\delta_{\mathrm{M}}$ & atmospheric carbon removal rate & 0.0833 \\
$\tau_{1}$ & parameter temperature relationship & 0.226 \\
$\tau_{2}$ & parameter temperature relationship & 0.44 \\
$\tau_{3}$ & parameter temperature relationship & 0.02 \\
$\lambda$ & parameter temperature relationship & 1.41 \\
$\mathrm{M}_{0}$ & initial carbon concentration & 590 \\
$\mathrm{~T}_{0}^{\mathrm{a}}$ & initial temperature atmosphere & 0.50 \\
$\mathrm{~T}_{0}^{0}$ & initial temperature deep ocean & 0.10 \\
\hline
\end{tabular}

Regional Parameter Values

\begin{tabular}{lccccc}
\hline & $\theta_{\mathrm{i}, 1}$ & $\theta_{\mathrm{i}, 2}$ & $\mathrm{~b}_{\mathrm{i}, 1}$ & $\mathrm{~b}_{\mathrm{i}, 2}$ & $\rho_{\mathrm{i}}$ \\
\hline USA & 0.01102 & 2.0 & 0.07 & 2.887 & 0.015 \\
JPN & 0.01174 & 2.0 & 0.05 & 2.887 & 0.015 \\
EU & 0.01174 & 2.0 & 0.05 & 2.887 & 0.015 \\
CHN & 0.01523 & 2.0 & 0.15 & 2.887 & 0.030 \\
FSU & 0.00857 & 2.0 & 0.15 & 2.887 & 0.015 \\
ROW & 0.02093 & 2.0 & 0.10 & 2.887 & 0.030 \\
\hline
\end{tabular}

Variables in 1990 (Reference Year)*

\begin{tabular}{lrrrrrrrr}
\hline & \multicolumn{1}{c}{$\mathrm{Y}_{\mathrm{i}}^{0}$} & $(\%)$ & \multicolumn{1}{c}{$\mathrm{K}_{\mathrm{i}}^{0}$} & $(\%)$ & \multicolumn{1}{c}{$\mathrm{L}_{\mathrm{i}}^{0}$} & \multicolumn{1}{c}{$(\%)$} & \multicolumn{1}{c}{$\mathrm{E}_{\mathrm{i}}^{0}$} & \multicolumn{1}{c}{$(\%)$} \\
\hline USA & $5,464.796$ & 25.9 & $14,262.510$ & 26.3 & 250.372 & 4.8 & 1.360 & 20.5 \\
JPN & $2,932.055$ & 13.9 & $8,442.250$ & 15.6 & 123.537 & 2.4 & 0.292 & 10.9 \\
EU & $6,828.042$ & 32.4 & $18,435.710$ & 34.0 & 366.497 & 7.0 & 0.872 & 28.9 \\
CHN & 370.024 & 1.8 & $1,025.790$ & 1.9 & $1,133.683$ & 21.5 & 0.669 & 3.0 \\
FSU & 855.207 & 4.1 & $2,281.900$ & 4.2 & 289.324 & 5.5 & 1.066 & 6.8 \\
ROW & $4,628.621$ & 22.0 & $9,842.220$ & 18.1 & $3,102.689$ & 58.9 & 1.700 & 29.9 \\
\hline World & $21,078.750$ & 100.0 & $54,290.380$ & 100.0 & $5,266.100$ & 100.0 & 5.959 & 100.0 \\
\hline
\end{tabular}

* $\quad \mathrm{Y}_{\mathrm{i}}^{0}$ and $\mathrm{K}_{\mathrm{i}}^{0}$ million US\$, $\mathrm{L}_{\mathrm{i}}^{0}$ million people and $\mathrm{E}_{\mathrm{i}}^{0}$ giga tons. 


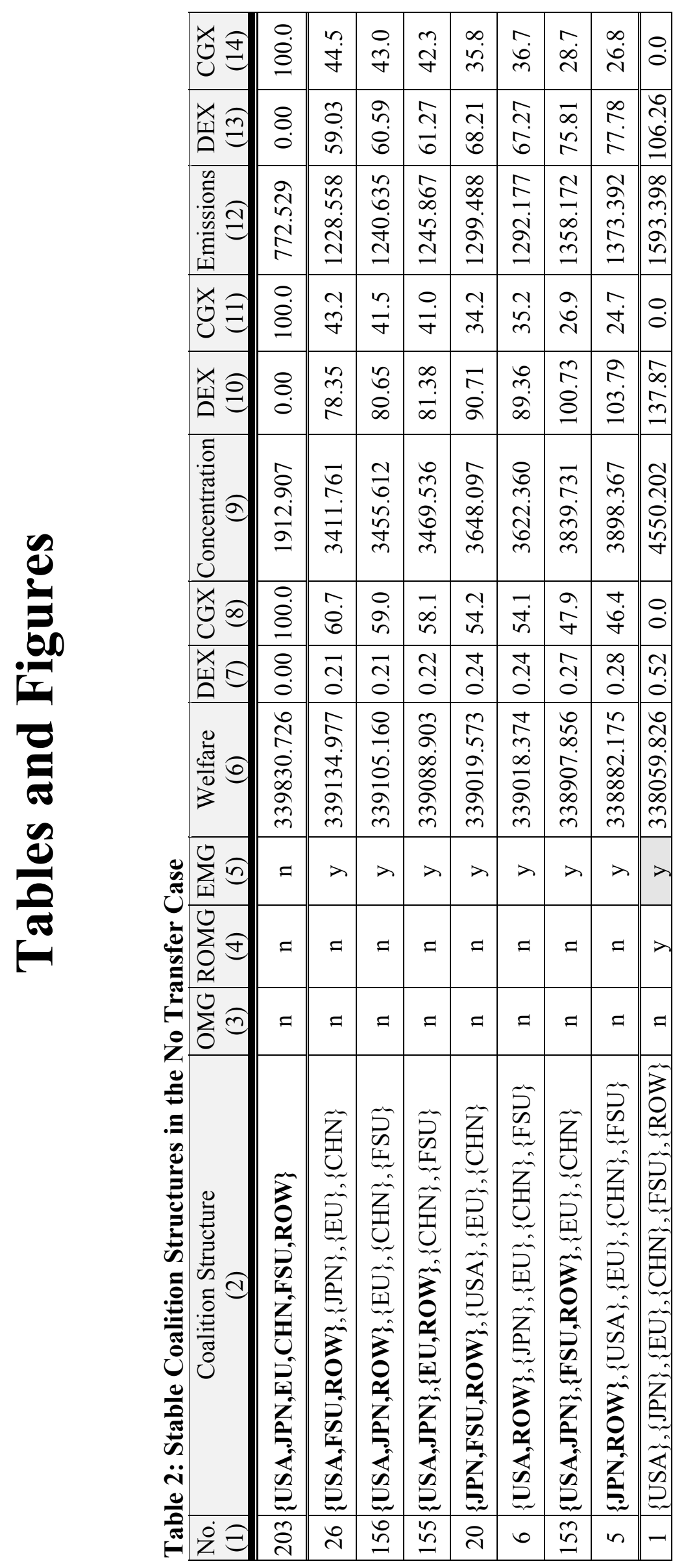




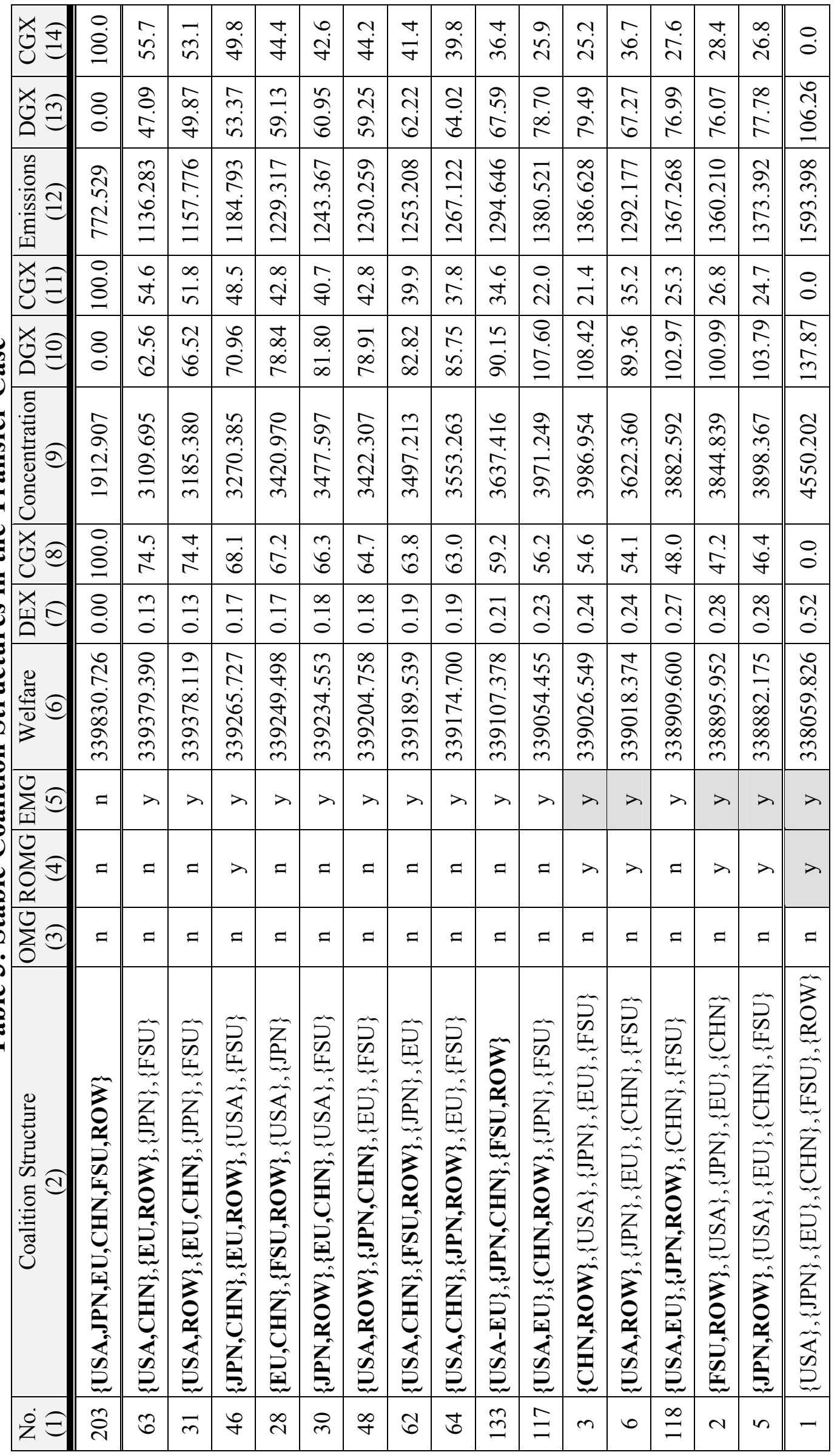


Figure 1: World Carbon Emissions $\left(\mathrm{GtCO}_{2}\right)$

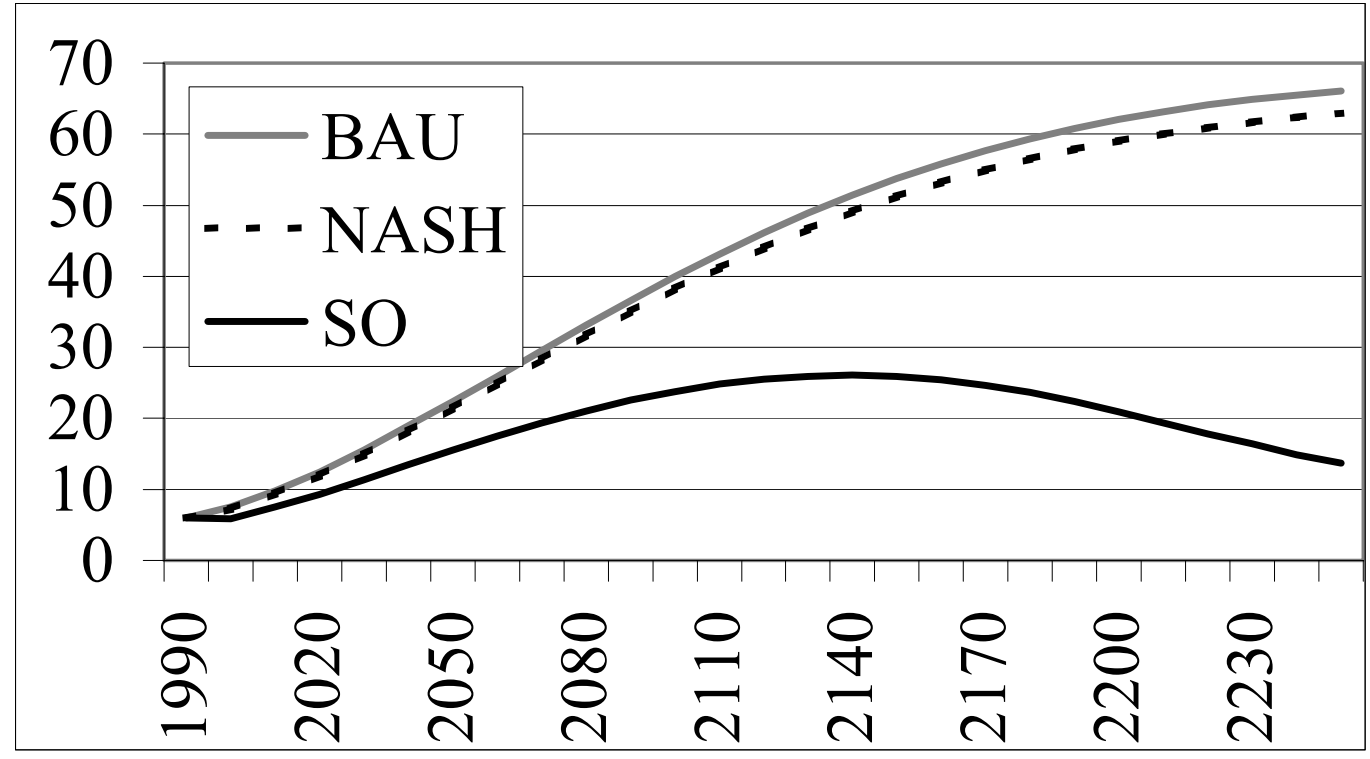

Figure 2: Atmospheric Carbon Concentration $\left(\mathrm{GtCO}_{2}\right)$

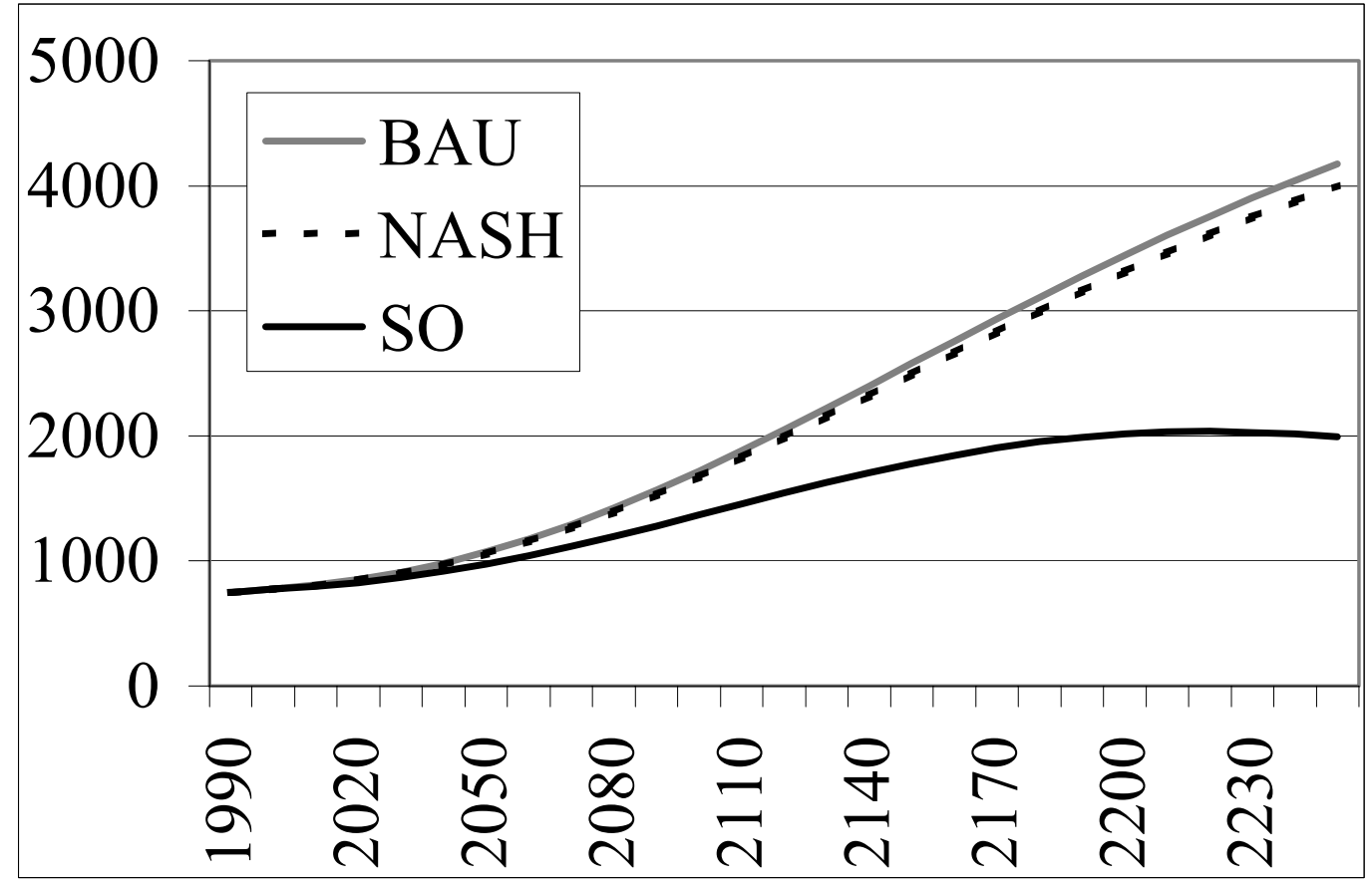


Figure 3: World GDP Composition in NASH scenario*

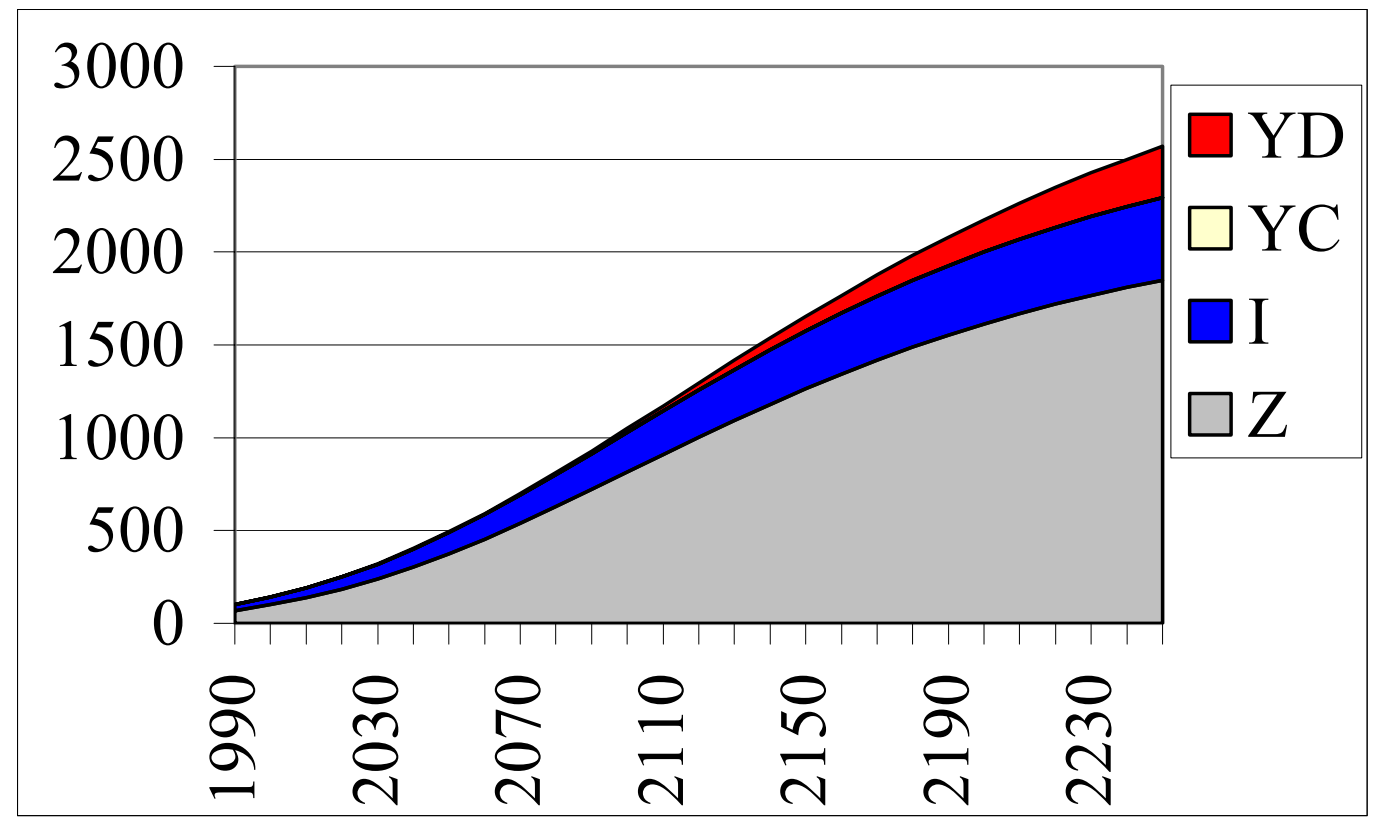

* $\mathrm{Y}=\mathrm{Z}+\mathrm{I}+\mathrm{YC}+\mathrm{YD}$ as in equation (1). World production in 1990 is nomalized to 100.

Figure 4: World GDP Composition in SO scenario*

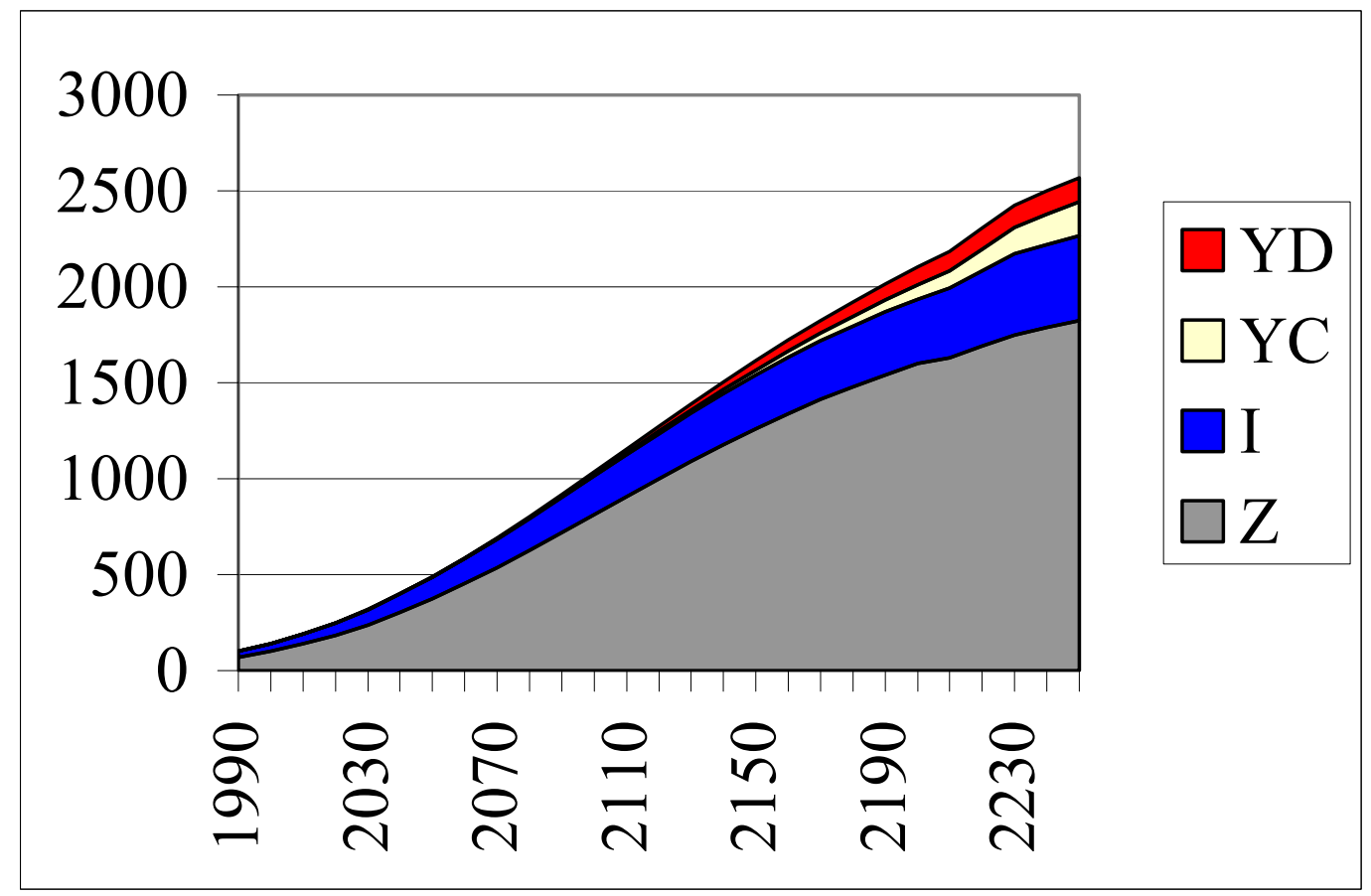

* $\mathrm{Y}=\mathrm{Z}+\mathrm{I}+\mathrm{YC}+\mathrm{YD}$ as in equation (1). World production in 1990 is nomalized to 100. 
The Center for Economic Studies (CES) is the research division of the Department of Economics of the Katholieke Universiteit Leuven. The CES research department employs some 100 people. The division Energy, Transport \& Environment (ETE) currently consists of about 15 full time researchers. The general aim of ETE is to apply state of the art economic theory to current policy issues at the Flemish, Belgian and European level. An important asset of ETE is its extensive portfolio of numerical partial and general equilibrium models for the assessment of transport, energy and environmental policies.

\section{ETE WORKING PAPER SERIES 2003}

$n^{\circ} 2003-17$

$n^{\circ} 2003-16$

$n^{\circ} 2003-15$

$n^{\circ} 2003-14$

$n^{\circ} 2003-13$

$n^{\circ} 2003-12$

$n^{\circ} 2003-11$

$n^{\circ} 2003-10$

$n^{\circ} 2003-09$

$n^{\circ} 2003-08$

$n^{\circ} 2003-07$

$n^{\circ} 2003-06$

$n^{\circ} 2003-05$
Eyckmans J., Finus M. (2003), Coalition Formation in a Global Warming Game: How the Design of Protocols Affects the Success of Environmental Treaty-Making

Eyckmans J., Schokkaert E. (2003), An "Ideal" Normative Theory for Greenhouse Negociations

Bigano A., Proost S. (2003), The opening of the European electricity market and environmental policy: does the degree of competition matter?

Pepermans G., Willems B. (2003), Regulating transmission in a spatial oligopoly: a numerical illustration for Belgium

Eyckmans J., Pepermans G. (2003), Is er toekomst voor kernenergie in België?

Franckx L. and D'Amato A. (2003), Environmental policy as a multi-task principal-agent problem

Proost S. And Van Dender K. (2003), Marginal Social Cost Pricing For All Transport Modes And The Effects Of Modal Budget Constraints

Mayeres I., Van Regemorter D. (2003), Modelling the health related benefits of environmental policies - a CGE ANALYSIS for the EU countries with GEM-E3

De Borger B., Proost S., Van Dender K. (2003), Congestion And Tax Competition In A Parallel Network

Pepermans G., Driesen J., Haeseldonckx D., D'haeseleer W. and Belmans R. (2003), Distributed generation: definition, benefits and issues

Moons E., The development and application of economic valuation techniques and their use in environmental policy - A survey

Muys B., Deckmyn G., Moons E., Quijano J.G., Proost S. and Ceulemans R. (2003), An integrated decision support tool for the prediction and evaluation of efficiency, environmental impact and total social cost of forestry projects in the framework of the Kyoto protocol

Proost, S. and Van Regemorter, D. (2003), Climate change policy in European countries and its effects on industry 